\title{
Oncolytic viruses: a step into cancer immunotherapy
}

This article was published in the following Dove Press journal:

Virus Adaptation and Treatment

23 December 201I

Number of times this article has been viewed

\section{Jonathan G Pol \\ Julien Rességuier \\ Brian D Lichty}

McMaster Immunology Research Centre, Department of Pathology and Molecular Medicine, McMaster University, Hamilton, Ontario, Canada
Correspondence: Brian Lichty

McMaster Immunology Research Centre, Department of Pathology and Molecular Medicine, McMaster University, 1280 Main Street West, Hamilton, Ontario, Canada L8S 4L8

Tel +l $9055259 \mid 40$ ext 22478

Fax + I 9055226750

Email lichtyb@mcmaster.ca
Abstract: Oncolytic virotherapy is currently under investigation in phase I-III clinical trials for approval as a new cancer treatment. Oncolytic viruses (OVs) selectively infect, replicate in, and kill tumor cells. For a long time, the therapeutic efficacy was thought to depend on the direct viral oncolysis (virocentric view). The host immune system was considered as a brake that impaired virus delivery and spread. Attention was paid primarily to approaches enhancing virus tumor selectivity and cytotoxicity and/or that limited antiviral responses. Thinking has changed over the past few years with the discovery that OV therapy was also inducing indirect oncolysis mechanisms. Among them, induction of an antitumor immunity following OV injection appeared to be a key factor for an efficient therapeutic activity (immunocentric view). Indeed, tumor-specific immune cells persist post-therapy and can search and destroy any tumor cells that escape the OVs, and thus immune memory may prevent relapse of the disease. Various strategies, which are summarized in this manuscript, have been developed to enhance the efficacy of OV therapy with a focus on its immunotherapeutic aspects. These include genetic engineering and combination with existing cancer treatments. Several are currently being evaluated in human patients and already display promising efficacy.

Keywords: oncolytic virus, cancer immunotherapy, tumor antigen, cancer vaccine, combination strategies

\section{Cancer and the immune system}

In 2006, the World Health Organization reported cancer as the second cause of death in developed countries and the third cause worldwide. ${ }^{1}$ Numerous risk factors responsible for cancer development have been characterized, and two-thirds appeared to be associated with lifestyle. In high-income countries, smoking, alcohol use, and obesity represent the main risk factors. ${ }^{2}$ Age aside, other factors include an unhealthy diet and lack of exercise, chronic infection (eg, hepatitis B virus [HBV], hepatitis $\mathrm{C}$ virus, human papillomavirus [HPV], Helicobacter pylori), or exposure to carcinogens: natural (eg, aflatoxin B1), chemical (eg, benzene, arsenic), radionuclide, or radiation (eg, ultraviolet). Some inherited genetic factors can also predispose to cancer development (eg, mutations in BRCA1 and BRCA2 genes for breast cancer). ${ }^{3}$ Although treatments for the disease have significantly improved, conventional therapies still have limited effects against many forms of neoplasm. As a consequence, projections to 2030 are pessimistic, with an increased impact of cancers on global mortality. ${ }^{4}$ Thus, reducing cancer-associated mortality will mean behavioral changes together with improvement and expansion of therapeutic strategies. submit your manuscript $\mid$ www.dovepress.com

Dovepress

http://dx.doi.org/10.2147/VAAT.SI 2980
Virus Adaptation and Treatment 2012:4 I-2I

(C) 2012 Pol et al, publisher and licensee Dove Medical Press Ltd. This is an Open Access article which permits unrestricted noncommercial use, provided the original work is properly cited. 


\section{Carcinogenesis}

Upon exposure to the cancer risk factors mentioned, carcinogenesis takes decades in adults and occurs in three consecutive steps: initiation, promotion, and progression. Tumor initiation results from genetic and/or epigenetic mutations in growth-regulatory genes encoding tumor suppressors (eg, p53, $\mathrm{Rb}$ ) or proto-oncogenes (eg, Ras, Myc). Tumor promotion consists of expansion of some initiated cells that have acquired a growth advantage over noninitiated cells. During replication, cancer cells accumulate mutations affecting genes involved in various cellular functions such as gene regulation (eg, TP53, RB1, JUN, MYC), DNA repair (eg, BRCA1, ATM), DNA replication (eg, hTERT, CDC6), chromosome segregation (eg, BUB1B), cell cycle checkpoints (eg, TP53, CCND1, CDKN2), viability (eg, TP53, BCL2, PTEN), or intra-/inter-/ extracellular signalling components (eg, RAS, APC, AKT, EGFR, HER2, CDH1, CTNNB1). ${ }^{5-9}$ Tumor progression refers to the stepwise transformation of a benign tumor to a neoplasm and to malignancy. Hallmarks of tumor malignancy were summarized by Hanahan and Weinberg ${ }^{10}$ as follows: (1) sustaining proliferative signalling, (2) evading growth suppressors, (3) enabling replicative immortality, (4) resisting cell death, (5) inducing angiogenesis, and (6) activating invasion and metastasis.

\section{Cancer immunoediting}

Intrinsic and extrinsic tumor suppressor mechanisms help prevent or slow down carcinogenesis all through life. Intrinsic tumor suppressor mechanisms consist of DNA repair and the death of mutated cells through apoptosis or senescence. After cellular transformation occurs and intrinsic tumor suppression fails, extrinsic tumor suppressor mechanisms are engaged. Extrinsic tumor suppressor mechanisms refer to the involvement of the immune system in eliminating tumor cells or preventing their outgrowth. In 2001, Schreiber et al observed that the immune system not only protects the host against tumor formation but also shapes tumor immunogenicity. ${ }^{11}$ This notion led to revision of the cancer immunosurveillance hypothesis by introducing the concept of cancer immunoediting. ${ }^{12}$ They postulate that cancer immunoediting proceeds sequentially through three distinct phases termed elimination, equilibrium, and escape.

The elimination phase would correspond to cancer immunosurveillance in which innate (natural killer cells [NKs], dendritic cells [DCs], macrophages) and adaptive ( $\mathrm{T}$ cells and NK T cells) immune systems are involved in detecting and destroying developing tumors. Mechanisms involved in tumor recognition by the immune cells are not fully understood. Induction of type I interferons (IFNs) during early steps of tumor development, release of different damage-associated molecular patterns (DAMPs) from dying tumor cells or damaged tissues (eg, HMGB1), and expression of stress ligands (eg, NKG2D ligands MICA/B) on the surface of tumor cells have been described. Additionally, effective cancer immunosurveillance requires the expression of tumor antigens that are able to induce expansion of effector $\mathrm{CD}^{+}$and $\mathrm{CD} 8^{+} \mathrm{T}$ cells. ${ }^{13,14}$

A limited number of tumor cell variants can survive elimination and enter the equilibrium phase. Functionally, these surviving tumor cells appear dormant. Disruption of crosstalk between growth factor and adhesion signalling during the elimination phase is, in part, responsible for this state. ${ }^{15}$ During the equilibrium phase, which may last for the lifetime of the host, the adaptive immune system ( $\mathrm{T}$ cells, interleukin [IL]-12, and IFN- $\gamma$ ), but not innate immunity, prevents tumor outgrowth but also edits cancer immunogenicity. Indeed, by eliminating immunogenic tumor cells, $\mathrm{T}$ cells exert a selective pressure on occult tumor cell populations and may favor the emergence of variants able to escape immunity. ${ }^{13,14}$

Tumor cell variants that enter the escape phase evolve different processes to elude or inhibit immune recognition and/or destruction (Figure 1A). First, they are poorly immunogenic and no longer recognized by adaptive immunity due to antigen loss or defects in antigen processing or presentation (eg, decreased major histocompatibility complex [MHC] class I expression). Second, they become resistant to immune cytotoxic effect by overexpression of antiapoptotic molecules (eg, Bcl-2, Bcl-xL), persistent activation of pro-oncogenic transcription factors (eg, STAT3), or expression of surface molecules inducing cytotoxic T lymphocyte (CTL) killing (eg, FasL, PD-L1). Third, they can generate an immunosuppressive microenvironment by secreting cytokines that inhibit effector immune cell functions (eg, transforming growth factor [TGF]- $\beta$, IL-10, galectin-1, indoleamine 2,3-dioxygenase) or by recruiting effector cells of immunosuppression like regulatory $\mathrm{T}$ cells (Tregs) and myeloid-derived suppressor cells (MDSCs). MDSCs can block T-cell function by secreting TGF- $\beta$, arginase 1 , and nitric oxide synthase. Tregs can inhibit effector $\mathrm{T}$ cells by expressing PD-L1 and CTLA-4 on their surface or secreting TGF- $\beta$ and IL-10. Over time, these selected tumor cell variants acquire the capacity to grow, leading to clinically apparent disease. ${ }^{13,14}$ 
A

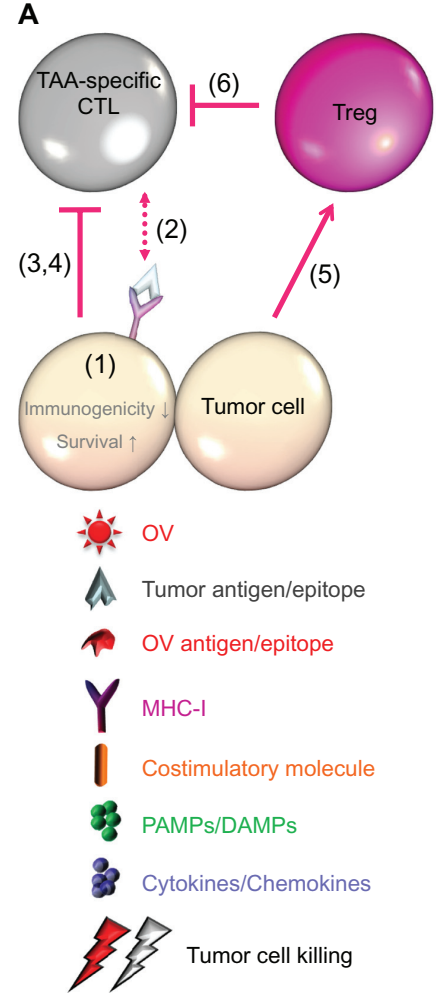

B

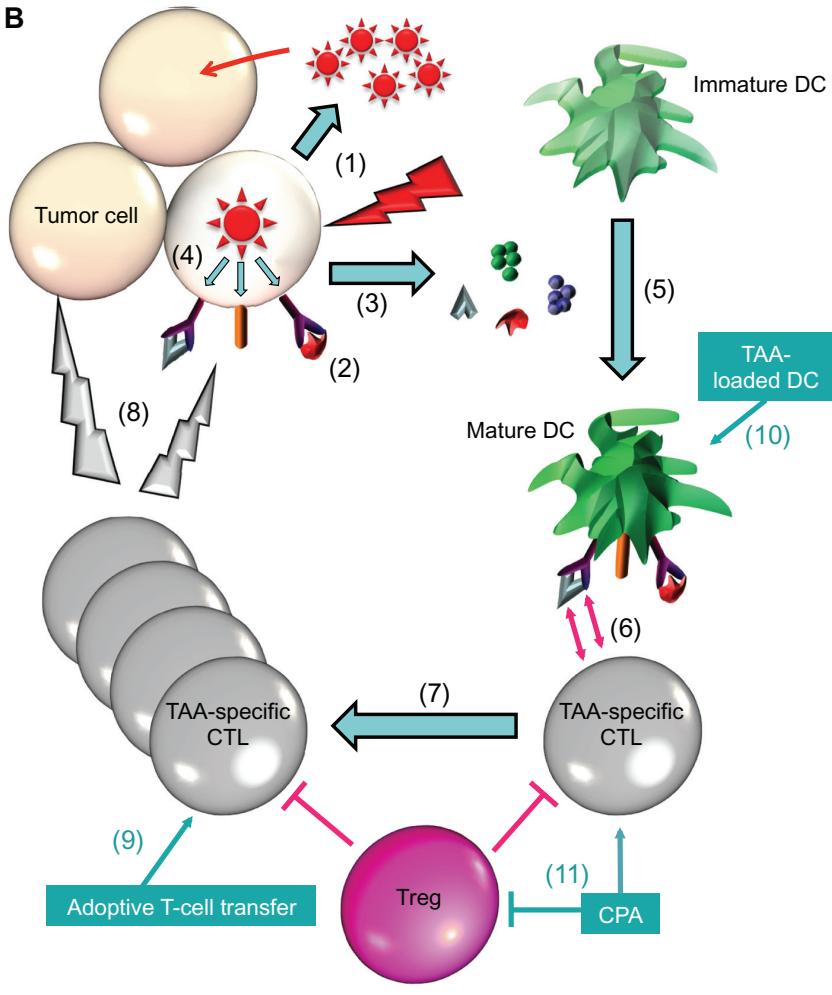

Figure I Tumor immunotolerance (A). Tumor cells evolve different processes to elude or inhibit immune recognition and/or destruction. (I,2) First, they are poorly immunogenic and no longer recognized by adaptive immunity due to antigen loss or defects in tumor-associated antigen (TAA) processing or presentation. Second, they become resistant to immune cytotoxic effect by overexpression of antiapoptotic molecules (eg, $\mathrm{Bcl}-2, \mathrm{Bcl}-\mathrm{xL}$ ) and persistent activation of pro-oncogenic transcription factors (eg, STAT3). Third, they can generate an immunosuppressive microenvironment by (3) expressing surface molecules that induce inactivation/killing of cytotoxic T lymphocytes (CTLs) (eg, FasL, PD-LI), (4) by secreting cytokines that inhibit effector immune cell functions (eg, transforming growth factor [TGF]- $\beta$, interleukin [IL]-I0, galectin-I, indoleamine 2,3-dioxygenase), or (5) by recruiting effector cells of immunosuppression-like regulatory $T$ cells (Tregs). (6) Tregs can inhibit effector $T$ cells by expressing PD-LI and CTLA-4 on their surface or secreting TGF- $\beta$ and IL-IO. (B) Oncolytic virotherapy as/in cancer immunotherapy. (I) Tumor cell infection by oncolytic viruses (OVs) leads to cell death and release of progeny virions that are able to infect adjacent tumor cells. Additionally, OV infection produces and releases immunostimulatory molecules that contribute to break immunotolerance and to reactivate antitumor immunity. (2,3) First, OV replication produces viral pathogen-associated molecular patterns (PAMPs) including viral antigens that can be presented onto the surface of infected tumor cells or released in the tumor microenvironment. (3) Second, stress induced by OV infection also releases cytokines and chemokines, damage-associated molecular patterns (DAMPs) (eg, HMGBI, uric acid, heat-shock proteins), and TAA. (4) Insertion of transgenes expressing TAA, cytokines/chemokines, or costimulatory molecules (eg, CD80) into OVs can improve stimulation of antitumor immunity. (5) All these immunostimulatory molecules contribute to dendritic cell (DC) maturation. $(6,7)$ After taking up released TAAs, mature DCs can present them to cognate T cells, including CTLs, which will undergo proliferation. (8) TAA-specific CTLs can then migrate to the tumor site and kill tumor cells that have not been infected by OVs. DC activation following OV therapy has also been described to stimulate natural killer cell-mediated antitumor activity. ${ }^{179,191,200} \mathrm{OV}$-induced antitumor immunity can be enhanced by combination with other cancer treatments such as cell therapies like (9) adoptive transfer of TAA-specific T cells and (I0) DC-based vaccines or immunomodulatory drugs like (I I) cyclophosphamide (CPA), which can both deplete Tregs and promote T-cell activation.

Abbreviation: MHC-I, major histocompatibility complex class I.

\section{Cancer immunotherapy}

Together with surgery, common cancer treatments consist of radiotherapy, chemotherapy, and immunotherapy. Alternatively, hormone therapy and tissue transplantation can be used to treat some neoplasms such as breast cancer (blocking estrogen synthesis or binding to its receptor) and lymphoma (bone marrow transplant). ${ }^{16,17}$ Radiotherapy and chemotherapy induce tumor cytotoxicity by breaking DNA (X-rays), blocking DNA replication (eg, cisplatin) or its transcription (eg, histone deacetylase inhibitors [HDACis]), and/or blocking mitosis (eg, paclitaxel). Immunotherapy mainly consists of stimulating the extrinsic tumor suppressor mechanisms by increasing the quality and/or quantity of immune effector cells, increasing tumor immunogenicity, or decreasing cancer-induced immunosuppressive mechanisms. Multiple immunotherapeutic strategies are being explored (for review, see Dougan and Dranoff ${ }^{18}$ ).

\section{Passive immunotherapy}

First, administration of monoclonal antibodies (mAbs) is a potent cancer treatment. Depending on the nature of the target (soluble or membrane-bound), binding of mAbs results in steric inhibition and neutralization, modulation of downstream signalling pathways, complement activation, 
and/or induction of the antibody-dependent cellular cytotoxicity. Twelve mAbs are clinically approved for treatment of various cancers. Nine are targeting tumor-associated surface proteins. Most of these targets are markers of hematologic tumors. Rituximab, ibritumomab tiuxetan, tositumomab, and ofatumumab bind to CD20 (associated to non-Hodgkin's lymphoma and chronic lymphocytic leukemia [CLL]), alemtuzumab binds to CD52 (CLL), and gemtuzumab ozogamicin binds to CD33 (acute myeloid leukemia). Trastuzumab, cetuximab, and panitumumab bind to epidermal growth factor receptor (EGFR) family members expressed on solid tumors. ${ }^{18,19}$ The last three mAbs approved do not directly target malignant cells. Bevacizumab binds to soluble vascular endothelial growth factor (VEGF), inhibiting tumor angiogenesis, while denosumab binds to RANKL, thus inhibiting osteoclast-mediated bone destruction and preventing skeletal-related events in patients with bone metastases. Finally, ipilimumab binds to CTLA-4 expressed on Tregs and CTL and blocks its inhibitory activity, thereby sustaining immune responses..$^{18,20,21}$

A second strategy for cancer immunotherapy consists of administering cytokines (eg, IL-2, IFN- $\alpha$, granulocytemacrophage colony-stimulating factor [GM-CSF]), adjuvants (eg, BCG, imiquimod), or immunomodulating agents (eg, thalidomide) to boost patient immune systems. Cytokines are also often used as adjuvants. IL-2 induces the proliferation of responsive T cells. GM-CSF stimulates the production of granulocytes and monocytes and promotes DC recruitment and activation. IFN- $\alpha$ shows pleiotropic effects. It increases tumor immunogenicity by upregulating genes encoding MHC-I and some tumor antigens, has antiangiogenic properties, promotes T- and B-cell activity, stimulates macrophages and DCs, and upregulates Fc receptors. ${ }^{22-27}$

Third, adoptive T-cell transfer strategy involves ex vivo identification and expansion of autologous or allogeneic tumor-specific lymphocytes that are then infused into cancer patients. So far, this approach is the most effective treatment for patients with metastatic melanoma. It can mediate objective cancer regression in approximately $50 \%$ of patients with metastatic melanoma refractory to all other treatments. Lymphocytes can be extracted from blood, tumor-draining lymph nodes, malignant effusions, or, if possible, from the tumor (tumor-infiltrating lymphocytes [TILs]) of patients. Their antitumor activity arises either naturally or after genetic engineering (eg, expression of tumor antigen-specific T-cell receptors). Ex vivo expansion (using growth factors such as IL-2) allows administration of 10-100 billion tumorspecific lymphocytes to patients. In vivo injection usually follows a lymphodepleting regimen (eg, body irradiation or cyclophosphamide/fludarabine chemotherapy) and often comes along with growth factors (eg, IL-2) or vaccines to stimulate survival and proliferation of infused lymphocytes..$^{28,29}$

\section{Active immunotherapy (cancer vaccines)}

All strategies mentioned previously depend on supplying the immune system with infused short-lived molecules or cells. Because the immune system is not directly engaged to fight the tumor (passive immunity), infusions must be repeated and treatment efficacy may not be optimal. In the last decade, cancer vaccine strategies have expanded. They aim at priming an endogenous antitumor response to generate active immunity. Because some cancers are caused by chronic infections, therapies that clear or prevent infection of the corresponding agent are defined as prophylactic cancer vaccines (eg, HBV and HPV16/18 vaccines against liver and cervical cancers, respectively, or antibiotics versus $\mathrm{H}$. pylori against stomach cancer). Their efficacy relies on priming an immune response specific to foreign antigens expressed by the infectious agent. The development of therapeutic cancer vaccines is much more challenging. Indeed, their efficacy depends on priming a response against an established tumor mediating immune tolerance. Many approaches for therapeutic cancer vaccines have been attempted with limited efficacy so far. Antigenspecific, idiotype-specific, DC-based, and whole tumor cellbased vaccines currently figure among the most promising.

DCs are the most potent professional antigen-presenting cells (APCs). They play a critical role in priming and regulating T- and B-cell responses. For this reason, their enrollment appears to be the key for the success of any vaccine approach. Immature DCs (iDCs) patrol in tissues looking for dying cells or pathogens. They undergo maturation once exposed to inflammatory signals (eg, TNF- $\alpha$, IL-1 $\beta$, IL-6), DAMPs (eg, HMGB1, heat-shock proteins [HSPs], nucleic acids), and/or pathogen-associated molecular patterns (PAMPs) (eg, LPS, dsRNA). Mature DCs have improved antigen-presenting abilities and increased expression of T-cell costimulatory molecules (CD80, CD83, CD86, CD40). They also acquire migratory potential by upregulating the chemotactic receptor CCR7, which will bring them to a lymph node or to the spleen. There, mature DCs will encounter and present antigen on MHC-II to cognate $\mathrm{CD} 4^{+} \mathrm{T}$ cells. Interaction between CD40 on the DCs and CD40L, expressed on the antigen-activated $\mathrm{CD} 4^{+} \mathrm{T}$ cell, induces the final maturation step of DCs, known as licensing. Licensed DCs upregulate additional cell surface products, such as OX40L and 4-1BBL, 
and present antigen on MHC-I to cognate $\mathrm{CD} 8^{+} \mathrm{T}$ cells. They also secrete IL-12 and stimulate survival and proliferation of antigen-activated $\mathrm{CD}^{+}$and $\mathrm{CD}^{+} \mathrm{T}$ cells through the crosslinking of 4-1BBL with 4-1BB expressed on activated $\mathrm{CD}^{+} \mathrm{T}$ cells, and of OX40L with OX40 expressed on activated $\mathrm{CD}^{+}{ }^{+}$cells. $^{30}$

Antigen-specific vaccines are based on the delivery of tumor antigens. Antigens are delivered as recombinant proteins ${ }^{31,32}$ or immunogenic peptides, ${ }^{33}$ often in combination with adjuvant $(\mathrm{eg}, \mathrm{CpG})$ or using naked plasmid DNA, ${ }^{34}$ bacterial vectors (eg, Salmonella typhimurium), ${ }^{35}$ or viral vectors (eg, recombinant poxviruses). ${ }^{36}$ In vivo, tumor antigens can then be taken up and presented by APCs and elicit cellular and humoural antitumor responses. Tumor antigens can be shared by both normal and tumor cells and described as tumor-associated antigens (TAAs), or expressed only on tumor cells and defined as tumor-specific antigens (TSAs). These antigens can be aberrantly expressed differentiation or embryonic markers, overexpressed or mutated cellular proteins, or viral proteins (eg, retrovirus, HBV). A list of characterized tumor antigens with their immunogenic epitopes is available at http:/www.cancerimmunity.org/ peptidedatabase/Tcellepitopes.htm. ${ }^{37} \mathrm{~A}$ wide range of neoplasms displays aberrant expression of differentiation factors that mainly belong to the cancer-testis antigen (CTA) family. Two CTA vaccines, against MAGE-A3 and NY-ESO-1 antigens, are being evaluated clinically. ${ }^{38}$ Results from numerous clinical trials in melanoma and nonsmall-cell lung cancer patients are encouraging, revealing their ability to elicit antitumor B- and T-cell responses. ${ }^{31,36,39-42}$

Idiotype-specific vaccines are based on immunization of patients against their own tumor idiotype. This type of vaccination is being improved for treating various cancers and, more particularly, mature B-cell neoplasms. ${ }^{43-45}$ Each plasma B cell produces one single kind of antibody. Antibodies produced are either secreted or anchored to the plasma membrane functioning as the B-cell receptor. The variable regions of the heavy and light chains of an immunoglobulin contain a unique set of antigenic determinants (idiotopes) called idiotypes. Idiotypes have the characteristics of tumor antigens, in this case the immunoglobulins expressed at the surface of malignant B cells, and can then be targeted with anti-idiotype antibodies. Idiotype-specific vaccines often include antiidiotype antibodies together with a carrier (eg, keyhole-limpet hemocyanin) and an adjuvant (eg, GM-CSF) to overcome immune tolerance. Several idiotype-specific vaccines have reached phase III clinical trials for the treatment of follicular lymphomas with limited results so far. ${ }^{43}$
DC-based vaccines consist of the autologous transfer of DCs loaded ex vivo with tumor antigen(s). DCs are often generated from circulating monocytes through culture in serum-free medium with GM-CSF in combination with IL-4 or IL-15. ${ }^{46}$ These iDCs are then loaded with TAA/TSA. Antigen(s) can be provided in many forms: (1) exogenously as peptides, protein, tumor lysate, complexed with antibody, or by fusing DCs with tumor cells (using polyethylene glycol or electrical fields) or (2) endogenously by transfection or transduction (eg, using adenoviral vector) of nucleic acids encoding a TAA/TSA. Loaded iDCs can be infused into a patient's tumor together with adjuvant (eg, TLR7 agonist imiquimod) to stimulate their maturation in situ or, more often, delivered subcutaneously or intravenously. ${ }^{47,48}$ These loaded iDCs can also be matured ex vivo prior to infusion. Protocols often involve their incubation with a cocktail of inflammatory cytokines (eg, TNF- $\alpha$, IL- $1 \beta$, IFN- $\alpha$, IFN- $\gamma$ ) together with activators of the TLR signalling (eg, polyI:C/ TLR3, LPS/TLR4, imiquimod/TLR7, CpG/TLR9). ${ }^{30,49}$ In addition, DCs can be modified ex vivo to express chemokines, cytokines, and costimulatory molecules to provide a more robust and persistent anticancer immunity in vivo (for review, see Boudreau et $\mathrm{al}^{50}$ ). Sipuleucel-T is a DC-based vaccine applied for treating patients with hormone-refractory prostate cancer. The vaccine is prepared from isolated DC precursors matured by incubation with a fusion protein consisting of GM-CSF and the cancer prostate antigen PAP. In April 2010, Sipuleucel-T became the first therapeutic cancer vaccine approved by the Food and Drug Administration, opening a new era for cancer vaccines. ${ }^{51,52}$

Tumor cell-based vaccines are made from autologous or allogeneic tumor cells removed during surgery and manipulated ex vivo. These cells are expanded in culture, then irradiated or lysed before their in vivo infusion, often together with adjuvants. To improve the vaccine potency, tumor cells can also be genetically modified to express cytokines (eg, GMCSF), growth factors (eg, EGF), human leucocyte antigen, or costimulatory molecules (eg, CD80). Compared with other cancer vaccine approaches, whole tumor cell vaccines are not restricted to a limited number of TAAs/TSAs. Patients'APCs are virtually able to take up the full pattern of tumor antigens (including undiscovered ones) and present it to T cells. As a consequence, the immune response primed is highly specific to the patient's tumor. However, induction of autoimmunity is more likely to occur. Several tumor cell vaccines have already reached phase III clinical trials with promising results (eg, autologous whole cell vaccine OncoVax given with BCG adjuvant for colon cancer). ${ }^{53}$ 


\section{Immunotherapy and combination strategies}

As mentioned, radio-, chemo-, and immunotherapies have limited clinical efficacy for many cancer types. Optimal cancer treatment would imply acting simultaneously on multiple "fronts" such as viability/growth/immunogenicity of tumor cells, quality/quantity of immune effector cells, or factors responsible for tumor immunosuppression, angiogenesis, and evasion. Thus, combining various therapeutic approaches that act separately or cooperatively on these "fronts" must be considered. Combination of passive immunotherapy with radiotherapy (ibritumomab tiuxetan, tositumomab), chemotherapy (gemtuzumab ozogamicin), or biotherapy (denileukin diftitox) as immunoconjugates has been approved for over a decade. ${ }^{18}$ Most of these immunoconjugates induce both direct and immunemediated tumor cytotoxicity. Combining immunotherapy with chemotherapy can appear antagonistic at first sight. Indeed, chemotherapy induces not only tumor cell apoptosis, which has been regarded as nonimmunogenic or even tolerogenic, but also lymphodepletion. However, several studies provide mounting evidence that, depending on the dose and timing of administration, some chemotherapeutic agents such as cyclophosphamide (CPA) can improve antitumor immunity. ${ }^{54,55} \mathrm{CPA}$ showed pleiotropic effect that covers most of the "fronts": (1) direct tumor cytotoxicity, (2) depletion of immunosuppressive Tregs, (3) activation and proliferation of T and B cells, (4) promote infiltration of tumor-specific lymphocytes inside the tumor, (5) increase number and activation status of myeloid DCs, and (6) promote emergence of tumor-infiltrating DCs secreting more IL-12 and less IL-10. ${ }^{54,56,57}$ Combining several immunotherapeutic approaches is also very promising. So far, this mostly implies coadministration of wellcharacterized adjuvants (eg, IL-2, GM-CSF, BCG) together with tumor-specific mAbs, adoptively transferred cells, or cancer vaccines to stimulate the recruitment and activity of immune effector cells. New adjuvants like TLR9 agonists and $\alpha$-galactosylceramide are also being tested. ${ }^{18}$ Approved mAbs such as ipilimumab and bevacizumab reducing, respectively, immunosuppression and angiogenesis may also become common additives. In the same perspective, new mAbs are currently being evaluated. They block immunosuppressive cytokines (eg, anti-IL-10, IL-13, TGF- $\beta$, or VEGF) or immune inhibitory signals in lymphocytes (eg, anti-PD-1) or their ligand (eg, anti-PD-L1), or act as agonist of immunostimulatory receptors (eg, anti-CD40,
4-1BB, OX34). ${ }^{18}$ Other immunotherapeutic combinations are being evaluated to improve efficacy of cancer vaccines, such as (1) combining cancer vaccine with mAbs targeting the same TAAs/TSAs, ${ }^{58,59}$ (2) sequential administration of cancer vaccines expressing/carrying the same TAAs/ TSAs (prime-boost strategy), ${ }^{60-64}$ or (3) targeting different TAAs/TSAs simultaneously. ${ }^{65,66}$ Finally, combining cancer immunotherapy with oncolytic virotherapy also raises a lot of hope and will be discussed in this review.

\section{Oncolytic viruses}

Oncolytic virotherapy consists of administering viruses that selectively infect, replicate in, and kill tumor cells with no or limited impact on normal tissues. Viral oncolytic properties have been reported since the middle of the 19th century, before the actual discovery of viruses. At that time, some patients with hematologic malignancy showed transient remission after naturally occurring infections. ${ }^{67}$ In 1949 , Moore ${ }^{68,69}$ demonstrated selective destruction of murine tumors by the Russian Far East encephalitis virus, opening the field of oncolytic virotherapy. After a peak of interest in the 1950s-60s with the first clinical trials, the field was nearly abandoned. Extended knowledge in virology and molecular biology led to its rebirth 20 years ago with the first human clinical trial using a recombinant oncolytic virus (OV). ${ }^{67,70}$ Since then, several viruses showing oncolytic ability have been identified and engaged in preclinical and clinical studies (Table 1). The first OV was approved in China in 2005 for treating nasopharyngeal cancer (in combination with chemotherapy), and several are undergoing phase III clinical trials in the US (Table 1). ${ }^{71,72}$

\section{Tumor selectivity}

OVs are human (eg, herpes simplex virus [HSV], adenovirus [Ad], measles virus [MV]) or veterinary (eg, vesicular stomatitis virus [VSV], Newcastle disease virus [NDV], myxomavirus [MYXV]) viruses engineered to have, or naturally having, little pathology in humans. Also, their oncotropism can be inherent or acquired after genetic engineering.

Inherent oncotropism refers to OVs that are naturally able to infect and replicate in tumor cells. First, it implies that tumor cells express the surface receptor(s) required for OV binding/entry. Expression of these surface receptors can be aspecific (eg, CAR for Ad, CD46/CD150 for MV) or specific to malignant phenotype (eg, overexpression of the high-affinity laminin receptor used by the Sindbis virus, ${ }^{112,113}$ 
Table I List of candidates for oncolytic virotherapy identified during the last 20 years

\begin{tabular}{|c|c|c|c|c|}
\hline Genome & Family & Genus & Strain(s) & $\begin{array}{l}\text { Evaluation stage }{ }^{a} / \text { patented } O V \\
\text { (cancer treated) }\end{array}$ \\
\hline \multirow[t]{18}{*}{ DNA } & Adenoviridae & Mastadenovirus & Human adenovirus $C$ serotype 5 & Phase I-II/ONYX-0I5 (HNSCC, oropharyngeal \\
\hline & & & & cancers - Clinicaltrials.gov identifier ${ }^{b}:$ \\
\hline & & & & NCT00006 I06); Approved in China/HIOI \\
\hline & & & & Oncorine (nasopharyngeal cancer) ${ }^{72,73}$ \\
\hline & & & Human adenovirus $C$ serotype 6 & Experimental $^{74}$ \\
\hline & & & Human adenovirus B serotype 3 & Experimental ${ }^{75}$ \\
\hline & & & Human adenovirus B serotype II & Experimental $^{76}$ \\
\hline & Herpesviridae & Simplexvirus & Herpes simplex virus I & $\begin{array}{l}\text { Phase III/OncoVEX }{ }^{\text {GM-CSF }} \text { (melanoma - Clinicaltrials. } \\
\text { gov identifier: NCT00769704) } \text { ) }^{71,77}\end{array}$ \\
\hline & & & Herpes simplex virus 2 & Preclinical (breast cancer, neuroblastoma) ${ }^{78,79}$ \\
\hline & & Varicellovirus & Bovine herpesvirus I & Experimental $^{80}$ \\
\hline & & & Suid herpesvirus I & Preclinical (bladder cancer) ${ }^{81}$ \\
\hline & & Rhadinovirus & Bovine herpesvirus 4 & Preclinical (glioma) $)^{82}$ \\
\hline & & & Herpesvirus saimiri & Experimenta $^{83}$ \\
\hline & Parvoviridae & Parvovirus & $\mathrm{H}-\mathrm{IPV}$ & $\begin{array}{l}\text { Phase I-II/ParvOryx (GBM - Clinicaltrials.gov } \\
\text { identifier: NCT0I30I430) }\end{array}$ \\
\hline & & & Minute virus of mice & Experimenta| $^{84}$ \\
\hline & Poxviridae & Orthopoxvirus & Vaccinia virus & $\begin{array}{l}\text { Phase II/JX-594 (HCC - Clinicaltrials.gov identifier: } \\
\text { NCT00554372) }\end{array}$ \\
\hline & & & Raccoonpox virus & Preclinical (colon carcinoma, glioma) ${ }^{86}$ \\
\hline & & Leporipoxvirus & Myxomavirus & Preclinical (glioma) $)^{87}$ \\
\hline \multirow[t]{23}{*}{ RNA } & Coronaviridae & Coronavirus & Feline infectious peritonitis virus & Experimental $^{88}$ \\
\hline & & & Murine hepatitis virus & Experimental $^{89}$ \\
\hline & Orthomyxoviridae & Influenzavirus & Influenza A & Experimental ${ }^{90}$ \\
\hline & Paramyxoviridae & Avulavirus & Newcastle disease virus & $\begin{array}{l}\text { Phase I-II (metastatic cancers, GBM - Clinicaltrials. } \\
\text { gov identifiers: NCT00348842, NCTOI I 74537) }\end{array}$ \\
\hline & & Morbillivirus & Measles virus & $\begin{array}{l}\text { Phase I (ovarian cancer, multiple myeloma, plasma } \\
\text { cell neoplasm - Clinicaltrials.gov identifiers: } \\
\text { NCT00408590, NCT004508I4) })^{91}\end{array}$ \\
\hline & & Respirovirus & Sendai virus & Preclinical $(G B M)^{92}$ \\
\hline & & Rubululavirus & Mumps virus & Experimental ${ }^{93}$ \\
\hline & Picornaviridae & Cardiovirus & Encephalomyocarditis virus & Experimental ${ }^{94,95}$ \\
\hline & & Enterovirus & Coxsackievirus A2I & $\begin{array}{l}\text { Phase I (melanoma, HNSCC - Clinicaltrials.gov } \\
\text { identifiers: NCT00832559, NCT00438009) }\end{array}$ \\
\hline & & & Coxsackievirus Al3, AI5, Al8 & Experimental ${ }^{96}$ \\
\hline & & & Poliovirus & Preclinical (neuroblastoma) ${ }^{97}$ \\
\hline & & & Echovirus I & Experimental ${ }^{98-100}$ \\
\hline & & & Bovine enterovirus & Experimental $^{101}$ \\
\hline & & Senecavirus & Seneca valley virus & $\begin{array}{l}\text { Phase I/NTX-10 (advanced solid tumors with } \\
\text { neuroendocrine features - Clinicaltrials.gov } \\
\text { identifier: NCT003 I4925) }\end{array}$ \\
\hline & Reoviridae & Orbivirus & Bluetongue virus-10 & Experimental $^{102}$ \\
\hline & & Orthoreovirus & Reovirus serotype 3 & $\begin{array}{l}\text { Phase III/Reolysin (HNSCC - Clinicaltrials.gov } \\
\text { identifier: NCT0I I 66542) }\end{array}$ \\
\hline & Retroviridae & Gammaretrovirus & (Moloney) Murine leukemia virus & Experimental $^{103,104}$ \\
\hline & & Spumavirus & Foamy virus & Experimental $^{105}$ \\
\hline & Rhabdoviridae & Vesiculovirus & Vesicular stomatitis virus & Phase I (HCC) $)^{106}$ \\
\hline & & & Maraba virus, Farmington virus & $\begin{array}{l}\text { Preclinical studies ongoing in our group and in } \\
\text { Stojdl's group (melanoma, glioma) }\end{array}$ \\
\hline & & & $\begin{array}{l}\text { Bahia Grande virus, Carajas virus, } \\
\text { Muir Springs virus, Tibrogargan virus }\end{array}$ & Experimental $^{107}$ \\
\hline & Togaviridae & Alphavirus & Semliki forest virus & Preclinical (ovarian cancer) ${ }^{108,109}$ \\
\hline & & & Sindbis virus & Experimental| 10,111 \\
\hline
\end{tabular}

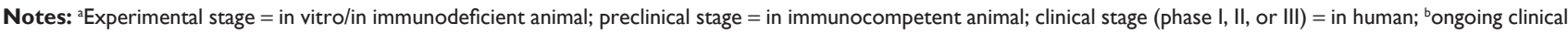
trials involving OVs are detailed in http://clinicaltrials.gov/; some corresponding identifier numbers are included in the table.

Abbreviations: GBM, glioblastoma multiforme; HCC, hepatocellular carcinoma; HNSCC, head and neck squamous cell carcinoma; OV, oncolytic virus. 
overexpression of ICAM-1 and DAF used by Coxsackievirus A21). ${ }^{114}$ Second, it implies that permissiveness of OV replication depends on factors associated with neoplasia. These factors include defective IFN response (eg, VSV, MYXV), ${ }^{115,116}$ aberrant cell cycle control (eg, parvovirus), ${ }^{117}$ resistance to apoptosis (eg, NDV), ${ }^{118}$ constitutive activation of Ras (eg, reovirus) ${ }^{119}$ or Akt (eg, MYXV), ${ }^{120}$ or, again, alteration of the extracellular matrix (eg, HSV-1). ${ }^{121}$

In most cases, viral oncotropism is genetically engineered. Genetic modifications aim at improving virus targeting to tumor cells, reducing virulence in normal tissues, and/or increasing dependency of OV genome expression/replication to the malignant phenotype.

Virus retargeting mainly involves fusing the virus attachment protein (eg, Ad fibre knob, MV hemagglutinin/H protein, HSV glycoprotein $\mathrm{C}$ ) to a single-chain antibody or a peptide known to bind a tumor-associated receptor. ${ }^{122-128}$ The receptor targeted can be overexpressed in a wide range of tumors (eg, EGFR, integrin $\alpha v \beta 6$, uPAR $)^{122,126,128}$ or limited to particular cancers (eg, EGFRvIII mutant/glioma, HER2/ breast cancer, PSMA/prostate cancer). ${ }^{123,125,127,129}$ Another way to improve OV targeting to tumor cells consists of rendering their binding/entry dependent on proteases secreted in the tumor microenvironment (eg, MMP, uPA). ${ }^{92,130,131}$ For example, the $\mathrm{F}$ protein of the Sendai virus needs to be cleaved by trypsin to allow fusion between viral and cellular membranes. Replacing the trypsin cleavage site by one of the uPA proteases, secreted in the extracellular matrix of solid tumors, limits virus infection to tumor tissue. ${ }^{92,130}$

Oncotropism can also be generated or improved by mutating viral genes required for virus survival in normal cells but not in malignant cells. For example, deletion/modification of the HSV genes encoding the neurovirulence factor ICP34.5 and the nucleotide reductase ICP6 abolishes its natural neurotropism without affecting its oncotropism. ${ }^{132,133}$ Deletion of E1A and E1B genes results in a restriction of Ad replication to cells with defects in $\mathrm{Rb}$ and $\mathrm{p} 53$-controlled tumor suppressor pathways. This defect is characteristic of well over $50 \%$ of tumor cells. ${ }^{134,135}$ Deletion of the vaccinia virus (VV) genes encoding the thymidine kinase (TK) and the vaccinia growth factor ensures that virus replication is limited to rapidly dividing cells. ${ }^{136}$ Oncotropism can also be ensured or improved by inserting regulatory elements in viral genes. These elements can be promoter sequence from active tumor genes (eg, hTERT promoter), ${ }^{137-140} 5^{\prime}$ UTR sequence recruiting tumor-associated translation factors (eg, eIF4E overexpressed in various cancers), ${ }^{141}$ or $3^{\prime}$ UTR sequence complementary to cellular miRNA (eg, let-7a miRNA downregulated in many tumors). ${ }^{142-145}$

\section{Tumor killing}

Tumor killing by OV can result directly from the viral cycle. Cell death can be the consequence of a lytic viral replication (eg, Ad, HSV). Some viral proteins can also induce apoptosis or necrosis, such as the adenoviral proteins E3 $11.6 \mathrm{~K}$ and E4ORF4 or the $\mathrm{F}$ protein of paramyxoviruses (eg, MV, NDV) responsible for syncytia formation. ${ }^{146,147}$ Autophagic cell death has also been described following infection of brain cancer-initiating cells with oncolytic Ad. ${ }^{148}$ Additionally, OVs can be genetically armed to improve direct oncolysis. In this case, cell death can be induced through transgene expression of viral or cellular proapoptotic proteins (eg, TRAIL, IL-24), ${ }^{149-153}$ tumor-suppressors (eg, p53, p16, SOCS3), ${ }^{154-156}$ or small hairpin RNA targeting factors involved in cell survival or proliferation (eg, hTERT, survivin, apollon, Ki67). ${ }^{157-161}$

The efficacy of oncolytic virotherapy also relies on indirect means of oncolysis. Among the mechanisms involved, stimulation of antitumor immunity plays a critical role. The discovery that OV therapy was acting like immunotherapy deeply redefined the strategies for applying OVs to cancer treatment. This point will be detailed in the next paragraphs. OV therapy can also induce tumor vasculature shutdown, leading to massive tumor necrosis. This phenomenon has been described, both in preclinical and clinical studies, following administration of oncolytic VSV and VV, respectively. ${ }^{162,163}$ Additionally, strategies involving genetic engineering have been developed to enhance indirect oncolysis. First, some recombinant OVs have been developed to sensitize tumor cells to chemotherapy. In this case, the OV expresses an enzyme that activates an administered prodrug. For example, the TK of herpesviruses converts ganciclovir into a guanine analog responsible for DNA synthesis inhibition and cell death. TK-expressing oncolytic Ad combined to ganciclovir have already shown efficacy against various types of cancers. ${ }^{134,164,165}$ Alternative combinations have been tested, converting prodrugs into other cytotoxic nucleotide analogs (eg, purine nucleoside phosphorylase/fludarabine, cytosine deaminase/5-fluorocytosine) or into alkylating agents (eg, nitroreductase/CB1954). ${ }^{166-169}$ Second, some OVs have been developed to sensitize tumor cells to radiotherapy. As examples, VSV, Ad, and MV expressing the sodium symporter NIS allowed tumor-targeted radio iodide uptake in multiple myeloma, prostate cancer, and hepatocellular 
carcinoma cells, respectively. This combination significantly improved the efficacy of OV therapy. ${ }^{170-175}$

\section{Oncolytic viruses as/in immunotherapy}

The field of viral oncolytics has come to recognize the importance of the host immune response in determining clinical outcomes. Immune responses against viral vectors likely impair viral oncolysis, thereby representing a barrier to clinical success. On the other hand, immune responses against the tumor should aid in tumor destruction and can potentially prevent disease relapse.

\section{Induction of antitumor immune responses following oncolytic virotherapy}

As mentioned, the impact of OVs is not restricted to direct tumor cytolysis but also depends on the resultant immune response. Tumor cell infection by OVs should be highly immunogenic due to cell death, production of cytokines and danger signals, and release of tumor antigens (Figure 1B). ${ }^{176-178}$ These changes inside the tumor bed may affect the established immunosuppressive microenvironment and initiate antitumor immunity.

As an illustration, melanoma cell lines infected with reovirus secreted the proinflammatory cytokines IL-6, IL-8, and IFN- $\beta$ together with the chemokines CXCL-10/ IP-10, CCL3/MIP-1 $\alpha$, CCL4/MIP-1 $\beta$, CCL5/RANTES, and CCL11/eotaxin. ${ }^{179-181}$ At the same time, some infected cell lines showed a decreased secretion of the immunosuppressive IL-10. ${ }^{181}$ Additionally, OV infection may be a source of immunogenic danger signals. First, it produces PAMPs: viral proteins and nucleic acids (dsRNA, unmethylated $\mathrm{CpG}$ motif DNA). Then, virus-induced stress and cell death programs may trigger the synthesis and spread of DAMPs in the tumor microenvironment. Immunogenicity of cell death depends on its type: necrosis, apoptosis, or autophagy, each of them differing by the pattern of cytokines and DAMPs produced (for review, see Kepp et $\mathrm{al}^{182}$ and Tesniere et al ${ }^{183}$ ). Release of intracellular HMGB1, uric acid, HSP70, or HSP27, related to necrosis, has been reported following infection with oncolytic Ad, VV, MV, or, again, NDV. ${ }^{177,184-187}$ To note, even apoptotic cell death can be immunogenic under certain circumstances. ${ }^{182,183}$ Finally, like tumor cell vaccines, viral oncolysis may also lead to the release of the whole set of TAAs/TSAs. ${ }^{188}$

Taken together, this cloud of inflammatory molecules facilitates immune cell recruitment and homing to the tumor and promotes their activation (Figure 1B). Among them, APCs, mainly DCs, can take up TAA/TSA from dying tumor cells (by phagocytosis) or released in the microenvironment (by extracellular processing and capture on empty surface MHC or by endocytosis). ${ }^{189,190}$ APCs are then able to crosspresent tumor antigens to the adaptive immune system, thereby leading to the induction of tumor-specific $\mathrm{T}$ cells. Such immune reaction has been characterized for reoviruses, both in vitro and in vivo, including clinical trials. In this case, tumor cell infection led to DC activation, which, in turn, stimulated the cytolytic ability of NK cells, expansion of T-cell populations, and induction of tumorspecific CTLs. ${ }^{178-181,191-193}$ A number of other studies have found that both innate and adaptive immune responses are generated following viral oncolysis mediated by HSV, ${ }^{79,194-198}$ adenovirus, ${ }^{177}$ parvovirus, ${ }^{199,200}$ and VSV. ${ }^{162,201,202}$ Antitumor immunity consecutive to viral oncolysis is an important aspect of this therapy, as CTLs will be able to recognize and destroy any remaining tumor cells that are not killed by the virus (Figure 1B). Moreover, preclinical studies showed that such OV-generated antitumor immunity may provide long-term tumor protection, preventing re-engraftment with the same tumor cells. ${ }^{180,195-198,203}$

\section{Immunostimulatory oncolytic viruses}

One strategy that has been investigated to increase the immunostimulatory properties of OVs is their combined use with cytokines/chemokines. ${ }^{204,205}$ As we have seen, recombinant cytokines have been used in the clinic as cancer immunotherapy. However, toxicities associated with higher doses of systemically administered cytokines are substantial. ${ }^{206}$ By incorporating cytokines and chemokines as a transgene into OVs, it is possible to safely increase immune stimulation through their local expression (Figure 1B). Various arms of the immune system can be targeted for stimulation by these transgenes. These could include APCs (DCs, macrophages, neutrophils) and/or lymphocytes (NK, NKT, T and B cells).

In an effort to recruit and activate APCs, a number of groups have added cytokines to their OVs such as GM-CSF ${ }^{77,163,207-212}$ or Flt3L, ${ }^{213,214}$ or chemokines like $\mathrm{CCL}^{213}$ or CCL5. ${ }^{215,216}$ Studies involving OV-mediated expression of GM-CSF started in 2001 in the HSV-1 backbone. ${ }^{217}$ Since then, GM-CSF has been inserted in many other OVs, including $\mathrm{VV}^{85,211,218,219} \mathrm{Ad}^{212,220,221}$ NDV, ${ }^{222} \mathrm{MV}^{223}$ and VSV. ${ }^{224}$ Oncolytic Ad (KH901), VV (JX-594), and HSV (OncoVEX) expressing GM-CSF 
have, respectively, reached clinical phase I, II, and III for the treatment of various neoplasms. . $7,85,207-212^{\text {JX-594 is an }}$ oncolytic VV deleted for viral TK and expressing human GM-CSF. In a preclinical context, JX-594 demonstrated significant antitumor efficacy, with concomitant induction of tumor-specific CTLs, in two liver tumor models, ${ }^{218}$ and this virus has been evaluated in clinical trials following intratumoral ${ }^{211}$ or systemic delivery. ${ }^{85}$ In a phase I trial, out of 21 patients suffering from different cancers and treated systemically with various doses of JX-594, eight showed progressive disease, one patient had a partial response, and 12 had stable disease, according to Response Evaluation Criteria in Solid Tumors. ${ }^{85}$

In order to stimulate lymphocytes, genes expressing other cytokines such as IL-12, ${ }^{206,225-228}$ IL-2, ${ }^{222,229,230}$ IL-4,$^{231,232}$ IL- $18,{ }^{225,233,234}$ IFN- $\alpha / \beta,{ }^{172,235-238}$ IFN- $\gamma,{ }^{239}$ or, again, TNF- $\alpha^{240}$ have been inserted into OVs. IL-12 targets NK, NKT, and T cells, inducing proliferation, expression of cytotoxic mediators, and production of cytokines. Among these cytokines figures IFN- $\gamma$, thereby inducing Th-1 CD4 ${ }^{+}$ T-cell response thought to yield superior antitumor immunity. ${ }^{241-243}$ Apart from its immunomodulatory role, IL-12 has also been shown to suppress tumor-associated angiogenesis, also in an IFN- $\gamma$-dependent manner ${ }^{244-247}$ As a consequence, exogenous administration of IL-12 impaired the growth of various tumors in vivo. ${ }^{248-251}$ However, its systemic delivery has been associated with substantial toxicity. ${ }^{252-255}$ Therefore, amount and tissue diffusion of IL-12 should be restricted. Such restriction has already demonstrated significant impact on tumor growth when IL-12 was expressed from the liver following hydrodynamic injection of DNA. ${ }^{256}$ Similarly, introduction of IL-12 transgene into OVs improved efficacy of OV therapy. ${ }^{206,226-228,257-259}$

Alternative strategies have been evaluated to improve $\mathrm{OV}$-induced antitumor immune response. These involved transgenes encoding costimulatory molecules (Figure 1B) such as CD80/B7-1, ${ }^{206,260} 4-1 \mathrm{BBL},{ }^{261,262}$ or CD40L ${ }^{232,263}$. Additionally, fusion proteins like CD80 fused to an Fc fragment of IgG1 (CD80-Ig) 233,234,264 or HSP proteins, which have the ability to chaperone peptides and activates APCs, ${ }^{265-268}$ have been added to OVs.

All these approaches contributed to increase efficacy of OV therapy in animal models. Some have also been evaluated in human patients with promising antitumor activity. ${ }^{77,211,212,265}$ Importantly, combining OV-mediated expression of both cytokines and costimulatory factors has been shown to further enhance the therapeutic efficacy. In this case, cytokines and costimulatory molecules can be coexpressed from the same OV or expressed from different ones that are coadministered. Various combinations have already been tested with success, such as GM-CSF+CD80, ${ }^{260,269}$ IL-12+4-1BBL, ${ }^{262}$ IL-12+CD80, ${ }^{206}$ IL-18+CD80-Ig, ${ }^{233}$ or even IL-12+IL-18+CD80-Ig. ${ }^{234}$

\section{Oncolytic viruses expressing tumor antigens (oncolytic vaccines)}

Vaccination against pathogens has been one of the great successes in medicine. The development of therapeutic cancer vaccines is far more challenging due to the fact that successful vaccines will have to target tumor-associated antigens that the host may be tolerized against and which must be tumorspecific to avoid toxicities.

Phase I and II clinical trials have been performed to assess the ability of viral vaccine vectors expressing tumor antigens to induce immune responses in cancer patients. Some examples of TAA that have been evaluated include 5T4, carcinoembryonic antigen, MAGE, and NY-ESO-1..$^{36,210,270-274}$ In these trials, some patients were found to develop an antibody and/or cell-mediated immune response against the immunizing antigen. When using viral vectors to raise immune responses versus self-antigens, it is possible that the overwhelming immune response to the viral antigens may have limited the expansion of specific immune responses to the TAA of interest. ${ }^{275}$ One method to circumvent this biology is through the use of heterologous prime-boost strategies where the priming and boosting vectors are immunologically distinct. The large majority of studies assessing heterologous vaccination have used a variety of poxviruses, as well as Ad and Semliki Forest virus. ${ }^{276-281}$ Using a heterologous boost led in most cases to an expansion of TAA-specific T cells in both murine models and clinical trials. However, the results vary and there is a need to identify pairs of vectors that work well together.

Although classical viral vaccine vectors are nonreplicating, the use of replicating OVs as vaccine vectors has begun to be interrogated and led to the introduction of the concept of oncolytic vaccines (Figure 1B). As with Ad and modified VV Ankara, other OVs can be engineered to express TAA/TSA. Along with expressing their TAA/ TSA transgene to induce a specific immune response, these viruses will also infect and debulk the tumor, thus leaving residual tumor for the immune system while releasing other tumor antigens that may allow for antigen spreading. VV, VSV, and NDV engineered to express model TAAs have been used in an attempt to lytically destroy the tumor while inducing a specific immune response. ${ }^{201,205,282}$ Importantly, 
we have recently shown that OVs expressing TAA can be excellent boosting vectors. ${ }^{108,188}$ Combining the benefits of viral oncolysis (tumor debulking and reversal of local immunosuppression) with that of heterologous prime-boost strategies has led to substantially enhanced therapeutic benefit in animal models. ${ }^{188}$

\section{Combining oncolytic viruses with cell (immuno)therapy}

Cell therapies are based on the adoptive transfer of immune cells (eg, T cells, DCs), tumor cells, or progenitor cells that have been manipulated ex vivo. Initially, the idea was to use these cells as a carrier or "Trojan horse" for OV to decrease their detection by the immune system (eg, neutralizing antibodies). The objective was to improve OV delivery to the tumor following systemic administration and so to enhance tumor oncolysis. ${ }^{283-289}$ Interestingly, some combinations between OV and cell therapies also happen to further enhance antitumor immunity, when compared with each therapy taken separately. ${ }^{290-295}$ Cytokine-induced killer (CIK) cells are tumor-trafficking, non-MHC-restricted, cytolytic immune cells targeting NKG2D ligands; ligands present on most tumor cells. These cells not only displayed potent antitumor efficacy but also were able to carry and deliver oncolytic VV to primary tumors and metastases. As a consequence, administration of VV-infected CIK cells mounted very efficient antitumor immunity characterized by an increased number of TILs and a decreased Treg population infiltrating the tumor. ${ }^{290,292,296}$ The tumor cell-based vaccine approach has also been combined to OV therapy. After ex vivo infection with OV (eg, parvovirus, NDV), tumor cells were lethally irradiated and injected in vivo. Such a combination demonstrated better efficacy to break immune tolerance and to generate antitumor immunity than the standard tumor cell-based vaccine. ${ }^{293,295}$ Extracts of tumor cells infected by OVs (oncolysates) have been used to pulse DCs. These pulsed DCs displayed better immunostimulatory properties than DCs pulsed with uninfected tumor cell lysate. ${ }^{187}$ After infection with some OVs (eg, reovirus, VSV), DCs display improved immunostimulatory ability, underwent activation, and acquired the capacity to prime TAA-specific T cells. ${ }^{180,297}$ Reovirus virotherapy was shown to enhance the efficacy of DC- or T cell-based anticancer immunotherapies and synergistically enhances the survival of tumor-bearing mice. ${ }^{180}$ Finally, we demonstrated that OVs carrying TAA transgenes could also be used to transduce DCs as a vaccine platform. ${ }^{297}$ The expression of TAA from VSV in transduced DCs was able to enhance tumor-specific CTL responses and very efficiently activate NK cells. Interestingly, in this model, although CTLs played a role in protection, NK cells appeared to be the main effectors responsible for tumor protection. ${ }^{297}$

\section{Assets, limitations, and improvements of oncolytic virotherapy}

For safety reasons, OV repertoire is currently restricted to viruses that are rendered non- or weakly pathogenic for humans. Coupled to a preferential targeting to and/or replication in tumor cells, it means that OV therapy has shown very limited toxicity. If required, OV replication could also be controlled by administering antiviral drugs, neutralizing antibodies, or type I IFNs. ${ }^{298,299}$ Symptoms commonly described are transient and include fever, headache, fatigue, flu-like symptoms, pain, and some events of hepatic dysfunction. ${ }^{209,211,300}$ Most of them remain tolerable when compared with side effects associated with common cancer treatments, mostly tumor-aspecific. Nausea, diarrhea, hair loss, anemia, infection, and infertility are frequently reported with chemo- and radiotherapies. Side effects following passive immunotherapy (eg, cytokine administration) are considerable and can be severe, such as allergic reaction, diabetes, or heart, liver, and thyroid problems.

Antitumor efficacy of OV therapy has often been limited for various reasons. First, numerous clinical trials performed so far involved intratumoral injection of the oncolytic agent. This route ensures that the $\mathrm{OV}$ is delivered at high dose to the tumor. Unfortunately, oncolytic efficacy may rapidly drop as tumor size increases. Indeed, OV infection mainly concerns tumor cells that are proximal to the injection site. Replication competency of OVs should contribute to viral spreading from cell to cell. However, diffusion of injected and progeny virions through the tumor environment may be limited. Genetic engineering helped overcome this issue by introducing transgenes affecting the extracellular matrix (eg, relaxin; for review, see Smith et $\mathrm{al}^{301}$ ). Additionally, for practical evidence, intratumoral delivery would limit OV therapy to surface neoplasms (eg, head and neck cancer, melanoma).

Intravenous OV delivery raises a lot of hope for treating the variety of neoplasms: hematologic or solid, primary, or metastatic forms. Unfortunately, through this route, it is likely that some viruses were trapped by off-target tissues (eg, liver, spleen) or failed to escape the vascular compartment. But the main obstacle for systemic delivery remains the components 
of the immune system (eg, neutralizing antibodies, complement activation). The nature of the OV administered represents a critical choice. ${ }^{302}$ Viruses such as VV or MV evolved to traffic in the bloodstream while Ad or HSV are more rapidly neutralized in the plasma. ${ }^{303-306}$ Additionally, natural human viruses may encounter pre-existing immunity in some patients. ${ }^{286,298,307}$ Various strategies have been developed to limit clearing of circulating OVs, including injection of virions displaying surface proteins unrecognized by neutralizing Ig, ${ }^{75,308,309}$ cell carriers, ${ }^{283,284,286-289}$ modulation of tumor vasculature, ${ }^{204}$ or transient immunosuppression. ${ }^{310-313}$ Systemic administration of OVs allows widespread infection of tumors. However, as is mentioned previously, the dose of virus that effectively reaches the target is lowered. To compensate, OV must be injected at high doses. ${ }^{85}$ Furthermore, rapidly primed antiviral immunity limits OV replication to a few days. Similarly, anticancer drugs and immunotherapeutic molecules also display short lifespan in the body, but repeated injections circumvent this limitation. Such approaches have been applied to OV therapy but are likely thwarted due to OV-specific immune responses.

Luckily, the efficacy of OV therapy is not limited to direct oncolysis. For some OVs, like VSV or VV, a limited number of infection sites can initiate tumor vasculature shutdown and lead to necrosis of the whole tumor mass. ${ }^{162}$ As we have seen, infection of tumor cells by OVs also contributes to breaking tumor immunotolerance and reactivating tumor suppression mechanisms. Antitumor immunity consecutive to viral oncolysis might actually be the key point determining the overall therapeutic efficacy. Not only does it allow for destruction of non OV-infected cells but also it may raise tumor-specific memory populations, preventing relapse of the disease. ${ }^{79,196-198}$

Interestingly, OV therapy appears to be particularly suitable for combination with other cancer treatments. Direct oncolysis can be enhanced by associating OVs with radiotherapy and/or chemotherapy (eg, HDACi, cisplatin, paclitaxel, rapamycin). ${ }^{184,209,291,314}$ Indirect oncolysis can be enhanced by combining OVs with antiangiogenic molecules administered either exogenously (eg, cRGD peptide, trichostatin A, bevacizumab) $)^{315-317}$ or as transgene (eg, endostatin, angiostatin, anti-VEGF signalling antibodies), ${ }^{317-323}$ or with mAbs targeting tumor-associated surface proteins (eg, cetuximab) ${ }^{288}$ Additionally, a multitude of strategies have been developed to improve OV-induced antitumor immunity. These included combination of OVs with tumor cell- and DC-based therapies ${ }^{50,293-295,297}$ or with immunomodulatory molecules (eg, cytokines, Treg-depleting mAbs, drugs like CPA). ${ }^{78,204,205,267,324}$ Inserting transgenes expressing immunostimulatory factors (eg, cytokines/ chemokines, costimulatory molecules) into OVs also displayed efficient enhancement of the antitumor activity in preclinical and clinical settings. ${ }^{163,206,211,215,260}$ Once again, the nature of the viral vector appeared to be of importance. For example, expressing CD40L from oncolytic HSV did improve antitumor activity, and no benefit was observed when inserted into VSV. ${ }^{232,263}$ Also, when combined with chemotherapy, particular attention must be paid to the dose and timing of administration of both viruses and drugs. Indeed, the transient lymphodepletion must not affect OVinduced antitumor immunity to avoid a deleterious impact on the therapeutic efficacy. ${ }^{325,326}$

With the approval of the DC-based vaccine Sipuleucel-T, therapeutic cancer vaccines officially joined the arsenal of cancer therapies. ${ }^{51,52}$ Among them, oncolytic vaccines represent a promising way for establishing potent tumorspecific response. Unlike antigen-, anti-idiotype-, or DCbased vaccines, viral oncolysis may present the full pattern of TAA to APCs. This approach is similar to tumor cellbased vaccines. However, OV therapy also produces viral TLR agonists that act as catalyzers for the activation of APCs, which are key players for priming specific antitumor response. From there, overexpression of particular TAAs, selected for their ability to expand tumor-specific CTLs, should improve therapeutic efficacy. ${ }^{201,205,282}$ For this purpose, effort must be maintained to identify highly immunogenic TAA/TSA. Moreover, we have recently shown that including oncolytic vaccines in a heterologous prime-boost can further enhance tumor-specific T-cell response but also reduce anti-OV cellular responses. ${ }^{188}$

Oncolytic viral therapy lends itself well to computer simulation, as there are at least two populations (virus and tumor) that interact, and this interaction can be mathematically modelled. A number of models have been published over the years. ${ }^{327-339}$ These models have predicted that replication rate of the virus, tumor size, ${ }^{335}$ cytotoxicity of the virus, ${ }^{334}$ and distribution of the virus ${ }^{337}$ are all important. They have also highlighted the potential for oscillating population sizes following infection ${ }^{327,330}$ and how this may be important for the ultimate outcome of virotherapy. Others have attempted to make predictions about how the number of viral doses impacts on outcome. ${ }^{328}$ Few have attempted to include the complicating influence of antiviral immunity where it has been shown to negatively impact outcome. ${ }^{339}$ 
The induction of strong innate immune responses has been predicted to aid therapy, however. ${ }^{335}$ Our group recently published a model that attempted to incorporate antitumoral and antiviral immunity, and this predicted that both viral oncolysis and antitumoral immunity were required for tumor clearance with extended longevity of viral replication, leading to further enhancement of treatment. ${ }^{340}$ Overall, most of these models provide predictions that are intuitive to those in the field. However it is likely that they will become more useful as they become ever more sophisticated. The danger lies in basing the math on inaccurate assumptions (we may not know enough) and in generating predictions that are not easily tested to validate the models.

Finally, in addition to the points mentioned, OV therapy is attractive for its relatively cheap and low time-consuming procedures, from ex vivo virus production and purification to in vivo injection(s) and follow-up. Additionally, positive interactions (additive or synergic) between OV therapy and other cancer treatments should reduce side effects, because smaller dosages of radiation or therapeutic agents could be administered.

\section{Conclusion and place in therapy}

OVs are starting to show promise in the clinic. These advances have required the use of larger doses of less attenuated viruses to begin to achieve robust infection and destruction of tumors. The most promising clinical candidates show evidence of induced antitumoral immunity, and this is most likely the path to success for these agents. We believe that oncolytic viral therapy occurs in two phases: an initial phase where the virus mediates direct oncolysis of tumor cells, leading to a second phase where an induced immune response continues to mediate tumor destruction and control after the viral vector has been cleared. To date, there have been limited opportunities to compare and contrast viruses being tested or to test their combination with thoughtful attempts to modify the immune system to benefit and enhance therapy. As the field matures and the first viruses become approved therapeutics, we will be able to contemplate these possibilities. Ultimately, most cancer therapies are applied in combination, and it is reasonable to predict that OVs will be as well. However, they are very different from those therapies currently in use, and the ways and means to combine these agents with other therapies may require novel clinical trial designs and considerable attention paid to the many facets of their therapeutic effects.

\section{Disclosure}

The authors report no conflicts of interest in relation to this article.

\section{References}

1. Lopez AD, Mathers CD, Ezzati M, et al. Global burden of disease and risk factors. Washington (DC): World Bank; 2006.

2. Danaei G, Vander Hoorn S, Lopez AD, et al. Causes of cancer in the world: comparative risk assessment of nine behavioural and environmental risk factors. Lancet. 2005;366:1784-1793.

3. McLaughlin JR, Risch HA, Lubinski J, et al. Reproductive risk factors for ovarian cancer in carriers of BRCA1 or BRCA2 mutations: a casecontrol study. Lancet Oncol. 2007;8:26-34.

4. Mathers CD, Loncar D. Projections of global mortality and burden of disease from 2002 to 2030. PLoS Med. 2006;3:e442.

5. Dixon K, Kopras E. Genetic alterations and DNA repair in human carcinogenesis. Semin Cancer Biol. 2004;14:441-448.

6. Borlado LR, Mendez J. CDC6: from DNA replication to cell cycle checkpoints and oncogenesis. Carcinogenesis. 2008;29:237-243.

7. Pearson CA, Prozialeck WC. E-cadherin, beta-catenin and cadmium carcinogenesis. Med Hypotheses. 2001;56:573-581.

8. Lengauer C, Wang Z. From spindle checkpoint to cancer. Nat Genet. 2004;36:1144-1145.

9. Hanks S, Coleman K, Reid S, et al. Constitutional aneuploidy and cancer predisposition caused by biallelic mutations in BUB1B. Nat Genet. 2004;36:1159-1161.

10. Hanahan D, Weinberg RA. Hallmarks of cancer: the next generation. Cell. 2011;144:646-674.

11. Shankaran V, Ikeda H, Bruce AT, et al. IFNgamma and lymphocytes prevent primary tumor development and shape tumor immunogenicity. Nature. 2001;410:1107-1111.

12. Dunn GP, Bruce AT, Ikeda H, et al. Cancer immunoediting: from immunosurveillance to tumor escape. Nat Immunol. 2002;3: 991-998.

13. Vesely MD, Kershaw MH, Schreiber RD, Smyth MJ. Natural innate and adaptive immunity to cancer. Annu Rev Immunol. 2011;29: 235-271.

14. Schreiber RD, Old LJ, Smyth MJ. Cancer immunoediting: integrating immunity's roles in cancer suppression and promotion. Science. 2011; 331:1565-1570.

15. Aguirre-Ghiso JA. Models, mechanisms and clinical evidence for cancer dormancy. Nat Rev Cancer. 2007;7:834-846.

16. Bernstein SH, Burack WR. The incidence, natural history, biology, and treatment of transformed lymphomas. Hematology Am Soc Hematol Educ Program. 2009:532-541.

17. Taylor HS, Manson JE. Update in hormone therapy use in menopause. J Clin Endocrinol Metab. 2011;96:255-264.

18. Dougan M, Dranoff G. Immune therapy for cancer. Annu Rev Immunol. 2009;27:83-117.

19. Wierda WG, Kipps TJ, Durig J, et al. Chemoimmunotherapy with ofatumumab, fludarabine, and cyclophosphamide (O-FC) in previously untreated patients with chronic lymphocytic leukemia. Blood. 2011;117: 6450-6458.

20. Stopeck AT, Lipton A, Body JJ, et al. Denosumab compared with zoledronic acid for the treatment of bone metastases in patients with advanced breast cancer: a randomized, double-blind study. J Clin Oncol. 2010;28:5132-5139.

21. Culver ME, Gatesman ML, Mancl EE, Lowe DK. Ipilimumab: a novel treatment for metastatic melanoma. Ann Pharmacother. 2011;45: $510-519$.

22. Di Lorenzo G, Perdona S, Damiano R, et al. Gemcitabine versus bacille Calmette-Guerin after initial bacille Calmette-Guerin failure in nonmuscle-invasive bladder cancer: a multicenter prospective randomized trial. Cancer. 2010;116:1893-1900. 
23. Boozari B, Mundt B, Woller N, et al. Antitumoral immunity by virusmediated immunogenic apoptosis inhibits metastatic growth of hepatocellular carcinoma. Gut. 2010;59:1416-1426.

24. Kirkwood JM, Tarhini AA, Moschos SJ, Panelli MC. Adjuvant therapy with high-dose interferon alpha $2 \mathrm{~b}$ in patients with high-risk stage IIB/III melanoma. Nat Clin Pract Oncol. 2008;5:2-3.

25. Atkins MB, Kunkel L, Sznol M, Rosenberg SA. High-dose recombinant interleukin-2 therapy in patients with metastatic melanoma: long-term survival update. Cancer J Sci Am. 2000;6(Suppl 1):S11-S14.

26. Atkins MB, Lotze MT, Dutcher JP, et al. High-dose recombinant interleukin 2 therapy for patients with metastatic melanoma: analysis of 270 patients treated between 1985 and 1993. J Clin Oncol. 1999;17: 2105-2116.

27. Hurteau JA, Brady MF, Darcy KM, et al. Randomized phase III trial of tamoxifen versus thalidomide in women with biochemical-recurrentonly epithelial ovarian, fallopian tube or primary peritoneal carcinoma after a complete response to first-line platinum/taxane chemotherapy with an evaluation of serum vascular endothelial growth factor (VEGF): a Gynecologic Oncology Group Study. Gynecol Oncol. 2010; 119:444-450.

28. Rosenberg SA, Yang JC, Sherry RM, et al. Durable complete responses in heavily pretreted patients with metastatic melanoma using $\mathrm{T}$ cell transfer immunotherapy. Clin Cancer Res. April 15, 2011. [Epub ahead of print.]

29. Rosenberg SA, Dudley ME. Adoptive cell therapy for the treatment of patients with metastatic melanoma. Curr Opin Immunol. 2009;21: 233-240.

30. Gilboa E. DC-based cancer vaccines. J Clin Invest. 2007;117: 1195-1203.

31. Valmori D, Souleimanian NE, Tosello V, et al. Vaccination with NYESO-1 protein and $\mathrm{CpG}$ in Montanide induces integrated antibody/Th1 responses and CD8 T cells through cross-priming. Proc Natl Acad Sci US A. 2007;104:8947-8952.

32. Harada N, Hoshiai K, Takahashi Y, et al. Preclinical safety pharmacology study of a novel protein-based cancer vaccine CHP-NY-ESO-1. Kobe J Med Sci. 2008;54:E23-E34.

33. Odunsi K, Qian F, Matsuzaki J, et al. Vaccination with an NY-ESO-1 peptide of HLA class I/II specificities induces integrated humoral and T cell responses in ovarian cancer. Proc Natl Acad Sci U SA. 2007;104: $12837-12842$

34. Gnjatic S, Altorki NK, Tang DN, et al. NY-ESO-1 DNA vaccine induces T-cell responses that are suppressed by regulatory T cells. Clin Cancer Res. 2009;15:2130-2139.

35. Nishikawa $H$, Sato E, Briones G, et al. In vivo antigen delivery by a Salmonella typhimurium type III secretion system for therapeutic cancer vaccines. J Clin Invest. 2006;116:1946-1954.

36. Jager E, Karbach J, Gnjatic S, et al. Recombinant vaccinia/fowlpox NY-ESO-1 vaccines induce both humoral and cellular NY-ESO-1specific immune responses in cancer patients. Proc Natl Acad Sci USA. 2006;103:14453-14458.

37. Almeida LG, Sakabe NJ, deOliveira AR, et al. CT database: a knowledge-base of high-throughput and curated data on cancer-testis antigens. Nucleic Acids Res. 2009;37(database issue):D816-D819.

38. Caballero OL, Chen YT. Cancer/testis (CT) antigens: potential targets for immunotherapy. Cancer Sci. 2009;100:2014-2021.

39. Brichard VG, Lejeune D. GSK's antigen-specific cancer immunotherapy programme: pilot results leading to phase III clinical development. Vaccine. 2007;25(Suppl 2):B61-B71.

40. Gnjatic S, Nishikawa H, Jungbluth AA, et al. NY-ESO-1: review of an immunogenic tumor antigen. Adv Cancer Res. 2006;95:1-30.

41. Davis ID, Chen W, Jackson H, et al. Recombinant NY-ESO-1 protein with ISCOMATRIX adjuvant induces broad integrated antibody and CD4(+) and CD8(+) T cell responses in humans. Proc Natl Acad Sci US A. 2004;101:10697-10702.

42. Marchand M, van Baren N, Weynants P, et al. Tumor regressions observed in patients with metastatic melanoma treated with an antigenic peptide encoded by gene MAGE-3 and presented by HLA-A1. Int J Cancer. 1999;80:219-230.
43. Alvaro T, de la Cruz-Merino L, Henao-Carrasco F, et al. Tumor microenvironment and immune effects of antineoplastic therapy in lymphoproliferative syndromes. J Biomed Biotechnol. August 12, 2010. [Epub ahead of print.]

44. Alvarez-Rueda N, Ladjemi MZ, Behar G, et al. A llama single domain anti-idiotypic antibody mimicking HER 2 as a vaccine: Immunogenicity and efficacy. Vaccine. 2009;27:4826-4833.

45. Egri G, Takats A. Monoclonal antibodies in the treatment of lung cancer. Eur J Surg Oncol. 2006;32:385-394.

46. Palucka K, Ueno H, Banchereau J. Recent developments in cancer vaccines. J Immunol. 2011;186:1325-1331.

47. Nair S, McLaughlin C, Weizer A, et al. Injection of immature dendritic cells into adjuvant-treated skin obviates the need for ex vivo maturation. J Immunol. 2003;171:6275-6282.

48. Martin-Fontecha A, Sebastiani S, Hopken UE, et al. Regulation of dendritic cell migration to the draining lymph node: impact on T lymphocyte traffic and priming. J Exp Med. 2003;198:615-621.

49. Schuler G. Dendritic cells in cancer immunotherapy. Eur J Immunol. 2010;40:2123-2130.

50. Boudreau JE, Bonehill A, Thielemans K, Wan Y. Engineering dendritic cells to enhance cancer immunotherapy. Mol Ther. 2011;19: 841-853.

51. Kantoff PW, Higano CS, Shore ND, et al. Sipuleucel-T immunotherapy for castration-resistant prostate cancer. $N$ Engl J Med. 2010;363: 411-422.

52. Hovden AO, Appel S. The first dendritic cell-based therapeutic cancer vaccine is approved by the FDA. Scand J Immunol. 2010;72:554.

53. Mackiewicz J, Mackiewicz A. Gene-modified cellular vaccines: technologic aspects and clinical problems. Transplant Proc. 2010;42: 3287-3292.

54. Moschella F, Proietti E, Capone I, Belardelli F. Combination strategies for enhancing the efficacy of immunotherapy in cancer patients. Ann N Y Acad Sci. 2010;1194:169-178.

55. Nowak AK, Lake RA, Robinson BW. Combined chemoimmunotherapy of solid tumors: improving vaccines? Adv Drug Deliv Rev. 2006;58: 975-990.

56. Moschella F, Valentini M, Arico E, et al. Unraveling cancer chemoimmunotherapy mechanisms by gene and protein expression profiling of responses to cyclophosphamide. Cancer Res. 2011;71:3528-3539.

57. Antonarakis ES, Carducci MA. Combining low-dose cyclophosphamide with GM-CSF-secreting prostate cancer immunotherapy enhances antitumor immune effects. Expert Opin Investig Drugs. 2010; 19:311-314.

58. Orlandi F, Guevara-Patino JA, Merghoub T, et al. Combination of epitope-optimized DNA vaccination and passive infusion of monoclonal antibody against HER2/neu leads to breast tumor regression in mice. Vaccine. 2011;29:3646-3654.

59. Ladjemi MZ, Chardes T, Corgnac S, et al. Vaccination with human anti-trastuzumab anti-idiotype $\mathrm{scFv}$ reverses HER2 immunological tolerance and induces tumor immunity in MMTV.f.huHER2(Fo5) mice. Breast Cancer Res. 2011;13:R17.

60. Ribas A, Weber JS, Chmielowski B, et al. Intra-lymph node primeboost vaccination against melan $\mathrm{A}$ and tyrosinase for the treatment of metastatic melanoma: results of a phase 1 clinical trial. Clin Cancer Res. 2011;17:2987-2996.

61. Akbulut $\mathrm{H}$, Tang Y, Akbulut KG, et al. Addition of adenoviral vector targeting of chemotherapy to the MUC-1/ecdCD40L VPPP vector prime protein boost vaccine prolongs survival of mice carrying growing subcutaneous deposits of Lewis lung cancer cells. Gene Ther. 2010; 17:1333-1340.

62. Ishizaki H, Song GY, Srivastava T, et al. Heterologous prime/boost immunization with p53-based vaccines combined with toll-like receptor stimulation enhances tumor regression. J Immunother. 2010;33: 609-617.

63. Dangoor A, Lorigan P, Keilholz U, et al. Clinical and immunological responses in metastatic melanoma patients vaccinated with a highdose poly-epitope vaccine. Cancer Immunol Immunother. 2010;59: 863-873. 
64. Hodge JW, Higgins J, Schlom J. Harnessing the unique local immunostimulatory properties of modified vaccinia Ankara (MVA) virus to generate superior tumor-specific immune responses and antitumor activity in a diversified prime and boost vaccine regimen. Vaccine. 2009;27:4475-4482.

65. Adamina M, Rosenthal R, Weber WP, et al. Intranodal immunization with a vaccinia virus encoding multiple antigenic epitopes and costimulatory molecules in metastatic melanoma. Mol Ther. 2010;18: 651-659.

66. Kono K, Mizukami Y, Daigo Y, et al. Vaccination with multiple peptides derived from novel cancer-testis antigens can induce specific T-cell responses and clinical responses in advanced esophageal cancer. Cancer Sci. 2009;100:1502-1509.

67. Kelly E, Russell SJ. History of oncolytic viruses: genesis to genetic engineering. Mol Ther. 2007;15:651-659.

68. Moore AE. The destructive effect of the virus of Russian Far East encephalitis on the transplantable mouse sarcoma 180. Cancer. 1949;2: 525-534.

69. Moore AE. Inhibition of growth of five transplantable mouse tumors by the virus of Russian Far East encephalitis. Cancer. 1951;4:375-382.

70. Martuza RL, Malick A, Markert JM, et al. Experimental therapy of human glioma by means of a genetically engineered virus mutant. Science. 1991;252:854-856.

71. Rowan K. Oncolytic viruses move forward in clinical trials. J Natl Cancer Inst. 2010;102:590-595.

72. Garber K. China approves world's first oncolytic virus therapy for cancer treatment. J Natl Cancer Inst. 2006;98:298-300.

73. Pesonen S, Kangasniemi L, Hemminki A. Oncolytic adenoviruses for the treatment of human cancer: focus on translational and clinical data Mol Pharm. 2011;8:12-28.

74. Shashkova EV, May SM, Barry MA. Characterization of human adenovirus serotypes 5, 6, 11, and 35 as anticancer agents. Virology. 2009;394:311-320.

75. Hemminki O, Bauerschmitz G, Hemmi S, et al. Oncolytic adenovirus based on serotype 3. Cancer Gene Ther. 2011;18:288-296.

76. Silver J, Mei YF. Transduction and oncolytic profile of a potent replication-competent adenovirus $11 \mathrm{p}$ vector (RCAd1 1pGFP) in colon carcinoma cells. PLoS One. 2011;6:e17532.

77. Kaufman HL, Bines SD. OPTIM trial: a phase III trial of an oncolytic herpes virus encoding GM-CSF for unresectable stage III or IV melanoma. Future Oncol. 2010;6:941-949.

78. Li H, Zeng Z, Fu X, Zhang X. Coadministration of a herpes simplex virus-2 based oncolytic virus and cyclophosphamide produces a synergistic antitumor effect and enhances tumor-specific immune responses. Cancer Res. 2007;67:7850-7855.

79. Li H, Dutuor A, Tao L, et al. Virotherapy with a type 2 herpes simplex virus-derived oncolytic virus induces potent antitumor immunity against neuroblastoma. Clin Cancer Res. 2007;13:316-322.

80. Rodrigues R, Cuddington B, Mossman K. Bovine herpesvirus type 1 as a novel oncolytic virus. Cancer Gene Ther. 2010;17:344-355.

81. Shiau AL, Lin YP, Shieh GS, et al. Development of a conditionally replicating pseudorabies virus for HER-2/neu-overexpressing bladder cancer therapy. Mol Ther. 2007;15:131-138.

82. Redaelli M, Mucignat-Caretta C, Cavaggioni A, et al. Bovine herpesvirus 4 based vector as a potential oncolytic-virus for treatment of glioma. Virol J. 2010;7:298.

83. Stevenson AJ, Giles MS, Hall KT, et al. Specific oncolytic activity of herpesvirus saimiri in pancreatic cancer cells. $\mathrm{Br} J$ Cancer. August 2000;83:329-332.

84. Wollmann G, Tattersall P, van den Pol AN. Targeting human glioblastoma cells: comparison of nine viruses with oncolytic potential. JVirol. 2005;79:6005-6022.

85. Breitbach CJ, Burke J, Jonker D, et al. Intravenous delivery of a multimechanistic cancer-targeted oncolytic poxvirus in humans. Nature. 2011;477:99-102.

86. Evgin L, Vaha-Koskela M, Rintoul J, et al. Potent oncolytic activity of raccoonpox virus in the absence of natural pathogenicity. Mol Ther. 2010;18:896-902.
87. Lun X, Alain T, Zemp FJ, et al. Myxoma virus virotherapy for glioma in immunocompetent animal models: optimizing administration routes and synergy with rapamycin. Cancer Res. 2010;70:598-608.

88. Wurdinger T, Verheije MH, Raaben M, et al. Targeting non-human coronaviruses to human cancer cells using a bispecific single-chain antibody. Gene Ther. 2005;12:1394-1404.

89. Verheije MH, Lamfers ML, Wurdinger T, et al. Coronavirus genetically redirected to the epidermal growth factor receptor exhibits effective antitumor activity against a malignant glioblastoma. J Virol. 2009;83:7507-7516.

90. Sturlan S, Stremitzer S, Bauman S, et al. Endogenous expression of proteases in colon cancer cells facilitate influenza A viruses mediated oncolysis. Cancer Biol Ther. 2010;10:592-599.

91. Galanis E, Hartmann LC, Cliby WA, et al. Phase I trial of intraperitoneal administration of an oncolytic measles virus strain engineered to express carcinoembryonic antigen for recurrent ovarian cancer. Cancer Res. 2010;70:875-882.

92. Hasegawa Y, Kinoh H, Iwadate Y, et al. Urokinase-targeted fusion by oncolytic Sendai virus eradicates orthotopic glioblastomas by pronounced synergy with interferon-beta gene. Mol Ther. 2010;18: $1778-1786$.

93. Myers R, Greiner S, Harvey M, et al. Oncolytic activities of approved mumps and measles vaccines for therapy of ovarian cancer. Cancer Gene Ther. 2005;12:593-599.

94. Roos FC, Roberts AM, Hwang II, et al. Oncolytic targeting of renal cell carcinoma via encephalomyocarditis virus. EMBO Mol Med. 2010; 2:275-288

95. Adachi M, Brooks SE, Stein MR, et al. Destruction of human retinoblastoma after treatment by the E variant of encephalomyocarditis virus. J Neurooncol. 2006;77:233-240.

96. Au GG, Beagley LG, Haley ES, et al. Oncolysis of malignant human melanoma tumors by Coxsackieviruses A13, A15 and A18. Virol J. 2011;8:22.

97. Toyoda H, Wimmer E, Cello J. Oncolytic poliovirus therapy and immunization with poliovirus-infected cell lysate induces potent antitumor immunity against neuroblastoma in vivo. Int J Oncol. 2011;38: 81-87.

98. Haley ES, Au GG, Carlton BR, et al. Regional administration of oncolytic Echovirus 1 as a novel therapy for the peritoneal dissemination of gastric cancer. J Mol Med. 2009;87:385-399.

99. Berry LJ, Au GG, Barry RD, Shafren DR. Potent oncolytic activity of human enteroviruses against human prostate cancer. Prostate. 2008; 68:577-587.

100. Shafren DR, Sylvester D, Johansson ES, et al. Oncolysis of human ovarian cancers by echovirus type 1. Int J Cancer. 2005;115:320-328.

101. Smyth M, Symonds A, Brazinova S, Martin J. Bovine enterovirus as an oncolytic virus: foetal calf serum facilitates its infection of human cells. Int J Mol Med. 2002;10:49-53.

102. Hu J, Dong CY, Li JK, et al. Selective in vitro cytotoxic effect of human cancer cells by bluetongue virus-10. Acta Oncol. 2008;47: 124-134

103. Kubo S, Haga K, Tamamoto A, et al. Adenovirus-retrovirus hybrid vectors achieve highly enhanced tumor transduction and antitumor efficacy in vivo. Mol Ther. 2011;19:76-82.

104. Duerner LJ, Schwantes A, Schneider IC, et al. Cell entry targeting restricts biodistribution of replication-competent retroviruses to tumor tissue. Gene Ther. 2008;15:1500-1510.

105. Heinkelein M, Hoffmann U, Lucke M, et al. Experimental therapy of allogeneic solid tumors induced in athymic mice with suicide genetransducing replication-competent foamy virus vectors. Cancer Gene Ther. 2005; 12:947-953.

106. Ausubel LJ, Meseck M, Derecho I, et al. Current good manufacturing practice production of an oncolytic recombinant vesicular stomatitis viral vector for cancer treatment. Hum Gene Ther. 2011;22: 489-497.

107. Brun J, McManus D, Lefebvre C, et al. Identification of genetically modified Maraba virus as an oncolytic rhabdovirus. Mol Ther. 2010;18:1440-1449. 
108. Zhang YQ, Tsai YC, Monie A, et al. Enhancing the therapeutic effect against ovarian cancer through a combination of viral oncolysis and antigen-specific immunotherapy. Mol Ther. 2010;18:692-699.

109. Quetglas JI, Ruiz-Guillen M, Aranda A, et al. Alphavirus vectors for cancer therapy. Virus Res. 2010;153:179-196.

110. Tseng JC, Granot T, Digiacomo V, et al. Enhanced specific delivery and targeting of oncolytic Sindbis viral vectors by modulating vascular leakiness in tumor. Cancer Gene Ther. 2010;17:244-255.

111. Unno Y, Shino Y, Kondo F, et al. Oncolytic viral therapy for cervical and ovarian cancer cells by Sindbis virus AR339 strain. Clin Cancer Res. 2005;11:4553-4560.

112. Berno V, Porrini D, Castiglioni F, et al. The $67 \mathrm{kDa}$ laminin receptor increases tumor aggressiveness by remodeling laminin-1. Endocr Relat Cancer. 2005;12:393-406.

113. Wang KS, Kuhn RJ, Strauss EG, et al. High-affinity laminin receptor is a receptor for Sindbis virus in mammalian cells. J Virol. 1992;66: 4992-5001.

114. Shafren DR, Au GG, Nguyen T, et al. Systemic therapy of malignant human melanoma tumors by a common cold-producing enterovirus, coxsackievirus a21. Clin Cancer Res. 2004;10:53-60.

115. Bartee E, McFadden G. Human cancer cells have specifically lost the ability to induce the synergistic state caused by tumor necrosis factor plus interferon-beta. Cytokine. 2009;47:199-205.

116. Noser JA, Mael AA, Sakuma R, et al. The RAS/Raf1/MEK/ERK signaling pathway facilitates VSV-mediated oncolysis: implication for the defective interferon response in cancer cells. Mol Ther. 2007;15: 1531-1536.

117. Rommelaere J, Geletneky K, Angelova AL, et al. Oncolytic parvoviruses as cancer therapeutics. Cytokine Growth Factor Rev. 2010;21: 185-195.

118. Mansour M, Palese P, Zamarin D. Oncolytic specificity of Newcastle disease virus is mediated by selectivity for apoptosis-resistant cells. J Virol. 2011;85:6015-6023.

119. Kelly K, Nawrocki S, Mita A, et al. Reovirus-based therapy for cancer. Expert Opin Biol Ther. 2009;9:817-830.

120. Stanford MM, McFadden G. Myxoma virus and oncolytic virotherapy: a new biologic weapon in the war against cancer. Expert Opin Biol Ther. 2007; 7:1415-1425.

121. Kolodkin-Gal D, Zamir G, Edden Y, et al. Herpes simplex virus type 1 preferentially targets human colon carcinoma: role of extracellular matrix. J Virol. 2008;82:999-1010.

122. Coughlan $\mathrm{L}$, Vallath $\mathrm{S}$, Saha $\mathrm{A}$, et al. In vivo retargeting of adenovirus type 5 to alphavbeta 6 integrin results in reduced hepatotoxicity and improved tumor uptake following systemic delivery. J Virol. 2009; 83:6416-6428.

123. Grandi P, Fernandez J, Szentirmai O, et al. Targeting HSV-1 virions for specific binding to epidermal growth factor receptor-vIII-bearing tumor cells. Cancer Gene Ther. 2010;17:655-663.

124. Menotti L, Nicoletti G, Gatta V, et al. Inhibition of human tumor growth in mice by an oncolytic herpes simplex virus designed to target solely HER-2-positive cells. Proc Natl Acad Sci U S A. 2009; 106:9039-9044.

125. Liu C, Hasegawa K, Russell SJ, et al. Prostate-specific membrane antigen retargeted measles virotherapy for the treatment of prostate cancer. Prostate. 2009;69:1128-1141.

126. Jing $\mathrm{Y}$, Tong $\mathrm{C}$, Zhang J, et al. Tumor and vascular targeting of a novel oncolytic measles virus retargeted against the urokinase receptor. Cancer Res. 2009;69:1459-1468.

127. Hasegawa K, Nakamura T, Harvey M, et al. The use of a tropismmodified measles virus in folate receptor-targeted virotherapy of ovarian cancer. Clin Cancer Res. 2006;12:6170-6178.

128. Nakamura T, Peng KW, Harvey M, et al. Rescue and propagation of fully retargeted oncolytic measles viruses. Nat Biotechnol. 2005;23:209-214.

129. Menotti L, Cerretani A, Campadelli-Fiume G. A herpes simplex virus recombinant that exhibits a single-chain antibody to HER2/neu enters cells through the mammary tumor receptor, independently of the gD receptors. J Virol. 2006;80:5531-5539.
130. Kinoh H, Inoue M, Komaru A, et al. Generation of optimized and urokinase-targeted oncolytic Sendai virus vectors applicable for various human malignancies. Gene Ther. 2009;16:392-403.

131. Springfeld C, von Messling V, Frenzke M, et al. Oncolytic efficacy and enhanced safety of measles virus activated by tumor-secreted matrix metalloproteinases. Cancer Res. 2006;66:7694-7700.

132. Wakimoto H, Kesari S, Farrell CJ, et al. Human glioblastoma-derived cancer stem cells: establishment of invasive glioma models and treatment with oncolytic herpes simplex virus vectors. Cancer Res. 2009;69:3472-3481.

133. Nakamura H, Kasuya H, Mullen JT, et al. Regulation of herpes simplex virus gamma(1)34.5 expression and oncolysis of diffuse liver metastases by Myb34.5. J Clin Invest. 2002;109:871-882.

134. Fukuda K, Abei M, Ugai H, et al. E1A, E1B double-restricted replicative adenovirus at low dose greatly augments tumor-specific suicide gene therapy for gallbladder cancer. Cancer Gene Ther. 2009;16: 126-136.

135. Fukuda K, Abei M, Ugai H, et al. E1A, E1B double-restricted adenovirus for oncolytic gene therapy of gallbladder cancer. Cancer Res. 2003;63:4434-4440.

136. Thorne SH, Hwang TH, O'Gorman WE, et al. Rational strain selection and engineering creates a broad-spectrum, systemically effective oncolytic poxvirus, JX-963. J Clin Invest. 2007;117: 3350-3358.

137. Doloff JC, Jounaidi Y, Waxman DJ. Dual E1A oncolytic adenovirus: targeting tumor heterogeneity with two independent cancer-specific promoter elements, DF3/MUC1 and hTERT. Cancer Gene Ther. 2011; 18:153-166.

138. Lee CY, Bu LX, DeBenedetti A, et al. Transcriptional and translational dual-regulated oncolytic herpes simplex virus type 1 for targeting prostate tumors. Mol Ther. 2010;18:929-935.

139. Zhang KJ, Wang YG, Cao X, et al. Potent antitumor effect of interleukin-24 gene in the survivin promoter and retinoblastoma double-regulated oncolytic adenovirus. Hum Gene Ther. 2009;20: 818-830.

140. Hardcastle J, Kurozumi K, Chiocca EA, Kaur B. Oncolytic viruses driven by tumor-specific promoters. Curr Cancer Drug Targets. 2007;7:181-189.

141. Hamada K, Zhang T, Desaki J, et al. Carrier cell-mediated cell lysis of squamous cell carcinoma cells by squamous cell carcinoma antigen 1 promoter-driven oncolytic adenovirus. J Gene Med. 2010;12:545-554.

142. Hikichi M, Kidokoro M, Haraguchi T, et al. MicroRNA regulation of glycoprotein B5R in oncolytic vaccinia virus reduces viral pathogenicity without impairing its antitumor efficacy. Mol Ther. 2011; 19:1107-1115

143. Kelly EJ, Hadac EM, Greiner S, Russell SJ. Engineering microRNA responsiveness to decrease virus pathogenicity. Nat Med. 2008;14: 1278-1283.

144. Ylosmaki E, Hakkarainen T, Hemminki A, et al. Generation of a conditionally replicating adenovirus based on targeted destruction of E1A mRNA by a cell type-specific MicroRNA. J Virol. 2008;82: 11009-11015.

145. Edge RE, Falls TJ, Brown CW, et al. A let-7 microRNA-sensitive vesicular stomatitis virus demonstrates tumor-specific replication. Mol Ther. 2008;16:1437-1443.

146. Bateman A, Bullough F, Murphy S, et al. Fusogenic membrane glycoproteins as a novel class of genes for the local and immune-mediated control of tumor growth. Cancer Res. 2000;60:1492-1497.

147. Heise C, Kirn DH. Replication-selective adenoviruses as oncolytic agents. J Clin Invest. 2000;105:847-851.

148. Jiang H, Gomez-Manzano C, Aoki H, et al. Examination of the therapeutic potential of Delta-24-RGD in brain tumor stem cells: role of autophagic cell death. J Natl Cancer Inst. 2007;99:1410-1414.

149. Wang H, Song X, Zhang H, et al. Potentiation of tumor radiotherapy by a radiation-inducible oncolytic and oncoapoptotic adenovirus in cervical cancer xenografts. Int J Cancer. 2012;130:443-453. 
150. Chen L, Chen D, Gong M, et al. Concomitant use of Ad5/35 chimeric oncolytic adenovirus with TRAIL gene and taxol produces synergistic cytotoxicity in gastric cancer cells. Cancer Lett. 2009;284: 141-148.

151. Wohlfahrt ME, Beard BC, Lieber A, Kiem HP. A capsid-modified, conditionally replicating oncolytic adenovirus vector expressing TRAIL Leads to enhanced cancer cell killing in human glioblastoma models. Cancer Res. 2007;67:8783-8790.

152. Zhao L, Dong A, Gu J, et al. The antitumor activity of TRAIL and IL-24 with replicating oncolytic adenovirus in colorectal cancer. Cancer Gene Ther. 2006;13:1011-1022.

153. Ebert O, Shinozaki K, Kournioti C, et al. Syncytia induction enhances the oncolytic potential of vesicular stomatitis virus in virotherapy for cancer. Cancer Res. 2004;64:3265-3270.

154. van Beusechem VW, van den Doel PB, Grill J, et al. Conditionally replicative adenovirus expressing p53 exhibits enhanced oncolytic potency. Cancer Res. 2002;62:6165-6171.

155. Ma J, He X, Wang W, et al. E2F promoter-regulated oncolytic adenovirus with p16 gene induces cell apoptosis and exerts antitumor effect on gastric cancer. Dig Dis Sci. 2009;54:1425-1431.

156. Cui Q, Jiang W, Wang Y, et al. Transfer of suppressor of cytokine signaling 3 by an oncolytic adenovirus induces potential antitumor activities in hepatocellular carcinoma. Hepatology. 2008;47: 105-112.

157. Liu XR, Cai Y, Cao X, et al. A new oncolytic adenoviral vector carrying dual tumor suppressor genes shows potent antitumor effect. $J$ Cell Mol Med. July 27, 2011. [Epub ahead of print.]

158. Zheng JN, Pei DS, Sun FH, et al. Inhibition of renal cancer cell growth by oncolytic adenovirus armed short hairpin RNA targeting hTERT gene. Cancer Biol Ther. 2009;8:84-91.

159. Zheng JN, Pei DS, Mao LJ, et al. Inhibition of renal cancer cell growth in vitro and in vivo with oncolytic adenovirus armed short hairpin RNA targeting Ki-67 encoding mRNA. Cancer Gene Ther. 2009;16:20-32.

160. Shen W, Wang CY, Wang XH, Fu ZX. Oncolytic adenovirus mediated Survivin knockdown by RNA interference suppresses human colorectal carcinoma growth in vitro and in vivo. J Exp Clin Cancer Res. 2009;28:81.

161. Chu L, Gu J, Sun L, et al. Oncolytic adenovirus-mediated shRNA against Apollon inhibits tumor cell growth and enhances antitumor effect of 5-fluorouracil. Gene Ther. 2008;15:484-494.

162. Breitbach CJ, De Silva NS, Falls TJ, et al. Targeting tumor vasculature with an oncolytic virus. Mol Ther. 2011;19:886-894.

163. Liu TC, Hwang T, Park BH, et al. The targeted oncolytic poxvirus JX-594 demonstrates antitumoral, antivascular, and anti-HBV activities in patients with hepatocellular carcinoma. Mol Ther. 2008;16: 1637-1642.

164. Ahn M, Lee SJ, Li X, et al. Enhanced combined tumor-specific oncolysis and suicide gene therapy for prostate cancer using M6 promoter Cancer Gene Ther. 2009;16:73-82.

165. Zheng FQ, Xu Y, Yang RJ, et al. Combination effect of oncolytic adenovirus therapy and herpes simplex virus thymidine kinase/ganciclovir in hepatic carcinoma animal models. Acta Pharmacol Sin. 2009;30:617-627.

166. Bossow S, Grossardt C, Temme A, et al. Armed and targeted measles virus for chemovirotherapy of pancreatic cancer. Cancer Gene Ther. 2011;18:598-608.

167. Chalikonda S, Kivlen MH, O’Malley ME, et al. Oncolytic virotherapy for ovarian carcinomatosis using a replication-selective vaccinia virus armed with a yeast cytosine deaminase gene. Cancer Gene Ther. 2008; 15:115-125.

168. Foloppe J, Kintz J, Futin N, et al. Targeted delivery of a suicide gene to human colorectal tumors by a conditionally replicating vaccinia virus. Gene Ther. 2008;15:1361-1371.

169. Braidwood L, Dunn PD, Hardy S, et al. Antitumor activity of a selectively replication competent herpes simplex virus (HSV) with enzyme prodrug therapy. Anticancer Res. 2009;29:2159-2166.
170. Hakkarainen T, Rajecki M, Sarparanta M, et al. Targeted radiotherapy for prostate cancer with an oncolytic adenovirus coding for human sodium iodide symporter. Clin Cancer Res. 2009;15:5396-5403.

171. Goel A, Carlson SK, Classic KL, et al. Radioiodide imaging and radiovirotherapy of multiple myeloma using VSV (Delta51)-NIS, an attenuated vesicular stomatitis virus encoding the sodium iodide symporter gene. Blood. 2007;110:2342-2350.

172. Li H, Peng KW, Dingli D, et al. Oncolytic measles viruses encoding interferon beta and the thyroidal sodium iodide symporter gene for mesothelioma virotherapy. Cancer Gene Ther. 2010;17: $550-558$.

173. Blechacz B, Splinter PL, Greiner S, et al. Engineered measles virus as a novel oncolytic viral therapy system for hepatocellular carcinoma. Hepatology. 2006;44:1465-1477.

174. Hasegawa K, Pham L, O'Connor MK, et al. Dual therapy of ovarian cancer using measles viruses expressing carcinoembryonic antigen and sodium iodide symporter. Clin Cancer Res. 2006;12:1868-1875.

175. Dingli D, Peng KW, Harvey ME, et al. Image-guided radiovirotherapy for multiple myeloma using a recombinant measles virus expressing the thyroidal sodium iodide symporter. Blood. 2004;103:1641-1646.

176. Benencia F, Courreges MC, Conejo-Garcia JR, et al. HSV oncolytic therapy upregulates interferon-inducible chemokines and recruits immune effector cells in ovarian cancer. Mol Ther. 2005;12: 789-802.

177. Endo Y, Sakai R, Ouchi M, et al. Virus-mediated oncolysis induces danger signal and stimulates cytotoxic T-lymphocyte activity via proteasome activator upregulation. Oncogene. 2008;27: 2375-2381.

178. Errington F, Steele L, Prestwich R, et al. Reovirus activates human dendritic cells to promote innate antitumor immunity. J Immunol. 2008; 180:6018-6026.

179. Steele L, Errington F, Prestwich R, et al. Pro-inflammatory cytokine/ chemokine production by reovirus treated melanoma cells is PKR/ NF-kappaB mediated and supports innate and adaptive anti-tumor immune priming. Mol Cancer. 2011;10:20.

180. Gujar SA, Marcato P, Pan D, Lee PW. Reovirus virotherapy overrides tumor antigen presentation evasion and promotes protective antitumor immunity. Mol Cancer Ther. 2010;9:2924-2933.

181. Errington F, White CL, Twigger KR, et al. Inflammatory tumor cell killing by oncolytic reovirus for the treatment of melanoma. Gene Ther. 2008;15:1257-1270.

182. Kepp O, Tesniere A, Schlemmer F, et al. Immunogenic cell death modalities and their impact on cancer treatment. Apoptosis. 2009; 14:364-375.

183. Tesniere A, Apetoh L, Ghiringhelli F, et al. Immunogenic cancer cell death: a key-lock paradigm. Curr Opin Immunol. 2008;20: 504-511.

184. Huang B, Sikorski R, Kirn DH, Thorne SH. Synergistic anti-tumor effects between oncolytic vaccinia virus and paclitaxel are mediated by the IFN response and HMGB1. Gene Ther. 2011;18:164-172.

185. Gauvrit A, Brandler S, Sapede-Peroz C, et al. Measles virus induces oncolysis of mesothelioma cells and allows dendritic cells to cross-prime tumor-specific CD8 response. Cancer Res. 2008;68: 4882-4892.

186. Guo ZS, Naik A, O'Malley ME, et al. The enhanced tumor selectivity of an oncolytic vaccinia lacking the host range and antiapoptosis genes SPI-1 and SPI-2. Cancer Res. 2005;65:9991-9998.

187. Bai L, Koopmann J, Fiola C, et al. Dendritic cells pulsed with viral oncolysates potently stimulate autologous $\mathrm{T}$ cells from cancer patients. Int J Oncol. 2002;21:685-694.

188. Bridle BW, Stephenson KB, Boudreau JE, et al. Potentiating cancer immunotherapy using an oncolytic virus. Mol Ther. 2010;184: 4269-4275.

189. Savina A, Amigorena S. Phagocytosis and antigen presentation in dendritic cells. Immunol Rev. 2007;219:143-156.

190. Santambrogio L, Sato AK, Carven GJ, et al. Extracellular antigen processing and presentation by immature dendritic cells. Proc Natl Acad Sci U S A. 1999;96:15056-15061. 
191. Prestwich RJ, Errington F, Steele LP, et al. Reciprocal human dendritic cell-natural killer cell interactions induce antitumor activity following tumor cell infection by oncolytic reovirus. J Immunol. 2009;183: 4312-4321.

192. White CL, Twigger KR, Vidal L, et al. Characterization of the adaptive and innate immune response to intravenous oncolytic reovirus (Dearing type 3) during a phase I clinical trial. Gene Ther. 2008;15:911-920.

193. Prestwich RJ, Errington F, Ilett EJ, et al. Tumor infection by oncolytic reovirus primes adaptive antitumor immunity. Clin Cancer Res. 2008;14:7358-7366.

194. Sobol PT, Boudreau JE, Stephenson K, et al. Adaptive antiviral immunity is a determinant of the therapeutic success of oncolytic virotherapy. Mol Ther. 2011;19:335-344.

195. Li H, Dutuor A, Fu X, Zhang X. Induction of strong antitumor immunity by an HSV-2-based oncolytic virus in a murine mammary tumor model. J Gene Med. 2007;9:161-169.

196. Hummel JL, Safroneeva E, Mossman KL. The role of ICP0-Null HSV-1 and interferon signaling defects in the effective treatment of breast adenocarcinoma. Mol Ther. 2005;12:1101-1110.

197. Nakamori M, Fu X, Rousseau R, et al. Destruction of nonimmunogenic mammary tumor cells by a fusogenic oncolytic herpes simplex virus induces potent antitumor immunity. Mol Ther. 2004;9:658-665.

198. Toda M, Iizuka Y, Kawase T, et al. Immuno-viral therapy of brain tumors by combination of viral therapy with cancer vaccination using a replication-conditional HSV. Cancer Gene Ther. 2002;9:356-364.

199. Moehler MH, Zeidler M, Wilsberg V, et al. Parvovirus H-1-induced tumor cell death enhances human immune response in vitro via increased phagocytosis, maturation, and cross-presentation by dendritic cells. Hum Gene Ther. 2005;16:996-1005

200. Bhat R, Dempe S, Dinsart C, Rommelaere J. Enhancement of NK cell anti-tumor responses using an oncolytic parvovirus. Int J Cancer. 2011;128:908-919.

201. Diaz RM, Galivo F, Kottke T, et al. Oncolytic immunovirotherapy for melanoma using vesicular stomatitis virus. Cancer Res. 2007;67: 2840-2848.

202. Wongthida P, Diaz RM, Galivo F, et al. Type III IFN interleukin-28 mediates the antitumor efficacy of oncolytic virus VSV in immune-competent mouse models of cancer. Cancer Res. 2010;70: 4539-4549.

203. Liu BL, Robinson M, Han ZQ, et al. ICP34.5 deleted herpes simplex virus with enhanced oncolytic, immune stimulating, and anti-tumor properties. Gene Ther. 2003;10:292-303.

204. Kottke T, Galivo F, Wongthida P, et al. Treg depletion-enhanced IL-2 treatment facilitates therapy of established tumors using systemically delivered oncolytic virus. Mol Ther. 2008;16:1217-1226.

205. Bronte V, Tsung K, Rao JB, et al. IL-2 enhances the function of recombinant poxvirus-based vaccines in the treatment of established pulmonary metastases. J Immunol. 15 1995;154:5282-5292.

206. Lee YS, Kim JH, Choi KJ, et al. Enhanced antitumor effect of oncolytic adenovirus expressing interleukin-12 and B7-1 in an immunocompetent murine model. Clin Cancer Res. 2006;12:5859-5868.

207. Senzer NN, Kaufman HL, Amatruda T, et al. Phase II clinical trial of a granulocyte-macrophage colony-stimulating factor-encoding, second-generation oncolytic herpesvirus in patients with unresectable metastatic melanoma. J Clin Oncol. 2009;27:5763-5771.

208. Hu JC, Coffin RS, Davis CJ, et al. A phase I study of OncoVEXGM$\mathrm{CSF}$, a second-generation oncolytic herpes simplex virus expressing granulocyte macrophage colony-stimulating factor. Clin Cancer Res. 2006;12:6737-6747.

209. Harrington KJ, Hingorani M, Tanay MA, et al. Phase I/II study of oncolytic HSV GM-CSF in combination with radiotherapy and cisplatin in untreated stage III/IV squamous cell cancer of the head and neck. Clin Cancer Res. 2010;16:4005-4015.

210. Kaufman HL, Kim DW, Deraffele G, et al. Local and distant immunity induced by intralesional vaccination with an oncolytic herpes virus encoding GM-CSF in patients with stage IIIc and IV melanoma. Ann Surg Oncol. 2010;17:718-730.
211. Park BH, Hwang T, Liu TC, et al. Use of a targeted oncolytic poxvirus, JX-594, in patients with refractory primary or metastatic liver cancer: a phase I trial. Lancet Oncol. 2008;9:533-542.

212. Chang J, Zhao X, Wu X, et al. A phase I study of KH901, a conditionally replicating granulocyte-macrophage colony-stimulating factor: armed oncolytic adenovirus for the treatment of head and neck cancers. Cancer Biol Ther. 2009;8:676-682.

213. Ramakrishna E, Woller N, Mundt B, et al. Antitumoral immune response by recruitment and expansion of dendritic cells in tumors infected with telomerase-dependent oncolytic viruses. Cancer Res. 2009; 69:1448-1458.

214. Bernt KM, Ni S, Tieu AT, Lieber A. Assessment of a combined, adenovirus-mediated oncolytic and immunostimulatory tumor therapy. Cancer Res. 2005;65:4343-4352.

215. Li J, O’Malley M, Urban J, et al. Chemokine expression from oncolytic vaccinia virus enhances vaccine therapies of cancer. Mol Ther. 2011; 19:650-657.

216. Lapteva N, Aldrich M, Weksberg D, et al. Targeting the intratumoral dendritic cells by the oncolytic adenoviral vaccine expressing RANTES elicits potent antitumor immunity. J Immunother. 2009;32:145-156.

217. Wong RJ, Patel SG, Kim S, et al. Cytokine gene transfer enhances herpes oncolytic therapy in murine squamous cell carcinoma. Hum Gene Ther. 2001;12:253-265.

218. Kim JH, Oh JY, Park BH, et al. Systemic armed oncolytic and immunologic therapy for cancer with JX-594, a targeted poxvirus expressing GM-CSF. Mol Ther. 2006;14:361-370.

219. Lee JH, Roh MS, Lee YK, et al. Oncolytic and immunostimulatory efficacy of a targeted oncolytic poxvirus expressing human GM-CSF following intravenous administration in a rabbit tumor model. Cancer Gene Ther. 2010;17:73-79.

220. Cerullo V, Pesonen S, Diaconu I, et al. Oncolytic adenovirus coding for granulocyte macrophage colony-stimulating factor induces antitumoral immunity in cancer patients. Cancer Res. 2010;70:4297-4309.

221. Robinson M, Li B, Ge Y, et al. Novel immunocompetent murine tumor model for evaluation of conditionally replication-competent (oncolytic) murine adenoviral vectors. J Virol. 2009;83:3450-3462.

222. Vigil A, Park MS, Martinez O, et al. Use of reverse genetics to enhance the oncolytic properties of Newcastle disease virus. Cancer Res. 2007;67:8285-8292.

223. Grote D, Cattaneo R, Fielding AK. Neutrophils contribute to the measles virus-induced antitumor effect: enhancement by granulocyte macrophage colony-stimulating factor expression. Cancer Res. 2003; 63:6463-6468

224. Bergman I, Griffin JA, Gao Y, Whitaker-Dowling P. Treatment of implanted mammary tumors with recombinant vesicular stomatitis virus targeted to Her2/neu. Int J Cancer. 2007;121:425-430.

225. Choi IK, Lee JS, Zhang SN, et al. Oncolytic adenovirus co-expressing IL-12 and IL-18 improves tumor-specific immunity via differentiation of T cells expressing IL-12Rbeta(2) or IL-18Ralpha. Gene Ther. 2011;18:898-909.

226. Varghese S, Rabkin SD, Liu R, et al. Enhanced therapeutic efficacy of IL-12, but not GM-CSF, expressing oncolytic herpes simplex virus for transgenic mouse derived prostate cancers. Cancer Gene Ther. 2006; $13: 253-265$

227. Derubertis BG, Stiles BM, Bhargava A, et al. Cytokine-secreting herpes viral mutants effectively treat tumor in a murine metastatic colorectal liver model by oncolytic and T-cell-dependent mechanisms. Cancer Gene Ther. 2007;14:590-597.

228. Shin EJ, Wanna GB, Choi B, et al. Interleukin-12 expression enhances vesicular stomatitis virus oncolytic therapy in murine squamous cell carcinoma. Laryngoscope. 2007;117:210-214.

229. Zhao H, Janke M, Fournier P, Schirrmacher V. Recombinant Newcastle disease virus expressing human interleukin-2 serves as a potential candidate for tumor therapy. Virus Res. 2008;136:75-80.

230. Carew JF, Kooby DA, Halterman MW, et al. A novel approach to cancer therapy using an oncolytic herpes virus to package amplicons containing cytokine genes. Mol Ther. 2001;4:250-256. 
231. Post DE, Sandberg EM, Kyle MM, et al. Targeted cancer gene therapy using a hypoxia inducible factor dependent oncolytic adenovirus armed with interleukin-4. Cancer Res. 2007;67:6872-6881.

232. Terada K, Wakimoto H, Tyminski E, et al. Development of a rapid method to generate multiple oncolytic HSV vectors and their in vivo evaluation using syngeneic mouse tumor models. Gene Ther. 2006;13: 705-714.

233. Fukuhara H, Ino Y, Kuroda T, et al. Triple gene-deleted oncolytic herpes simplex virus vector double-armed with interleukin-18 and soluble B7-1 constructed by bacterial artificial chromosome-mediated system. Cancer Res. 2005;65:10663-10668.

234. Ino Y, Saeki Y, Fukuhara H, Todo T. Triple combination of oncolytic herpes simplex virus-1 vectors armed with interleukin-12, interleukin-18, or soluble B7-1 results in enhanced antitumor efficacy Clin Cancer Res. 2006;12:643-652.

235. Shashkova EV, Kuppuswamy MN, Wold WS, Doronin K. Anticancer activity of oncolytic adenovirus vector armed with IFN-alpha and ADP is enhanced by pharmacologically controlled expression of TRAIL. Cancer Gene Ther. 2008;15:61-72.

236. Shashkova EV, Spencer JF, Wold WS, Doronin K. Targeting interferon-alpha increases antitumor efficacy and reduces hepatotoxicity of E1A-mutated spread-enhanced oncolytic adenovirus. Mol Ther. 2007;15:598-607.

237. Kirn DH, Wang Y, Le Boeuf F, et al. Targeting of interferon-beta to produce a specific, multi-mechanistic oncolytic vaccinia virus. PLoS Med. 2007;4:e353.

238. Willmon CL, Saloura V, Fridlender ZG, et al. Expression of IFN-beta enhances both efficacy and safety of oncolytic vesicular stomatitis virus for therapy of mesothelioma. Cancer Res. 2009;69:7713-7720.

239. Su C, Peng L, Sham J, et al. Immune gene-viral therapy with triplex efficacy mediated by oncolytic adenovirus carrying an interferongamma gene yields efficient antitumor activity in immunodeficient and immunocompetent mice. Mol Ther. 2006;13:918-927.

240. Han ZQ, Assenberg M, Liu BL, et al. Development of a secondgeneration oncolytic Herpes simplex virus expressing TNFalpha for cancer therapy. J Gene Med. 2007;9:99-106.

241. Trinchieri G. Interleukin-12 and the regulation of innate resistance and adaptive immunity. Nat Rev Immunol. 2003;3:133-146.

242. Nishimura T, Iwakabe K, Sekimoto M, et al. Distinct role of antigenspecific T helper type 1 (Th1) and Th2 cells in tumor eradication in vivo. $J$ Exp Med. 1999;190:617-627.

243. de Jong EC, Smits HH, Kapsenberg ML. Dendritic cell-mediated T cell polarization. Springer Semin Immunopathol. 2005;26:289-307.

244. Voest EE, Kenyon BM, O’Reilly MS, et al. Inhibition of angiogenesis in vivo by interleukin-12. J Natl Cancer Inst. 1995;87:581-586.

245. Cavallo F, Quaglino E, Cifaldi L, et al. Interleukin-12-activated lymphocytes influence tumor genetic programs. Cancer Res. 2001;61: 3518-3523.

246. Yao L, Sgadari C, Furuke K, et al. Contribution of natural killer cells to inhibition of angiogenesis by interleukin-12. Blood. 1999; 93:1612-1621.

247. Coughlin CM, Salhany KE, Gee MS, et al. Tumor cell responses to IFNgamma affect tumorigenicity and response to IL-12 therapy and antiangiogenesis. Immunity. 1998;9:25-34.

248. Nastala CL, Edington HD, McKinney TG, et al. Recombinant IL-12 administration induces tumor regression in association with IFNgamma production. J Immunol. 1994;153:1697-1706.

249. Tahara H, Zeh HJ 3rd, Storkus WJ, et al. Fibroblasts genetically engineered to secrete interleukin-12 can suppress tumor growth and induce antitumor immunity to a murine melanoma in vivo. Cancer Res. 1994;54:182-189.

250. Noguchi Y, Jungbluth A, Richards EC, Old LJ. Effect of interleukin-12 on tumor induction by 3-methylcholanthrene. Proc Natl Acad Sci US A. 1996;93:11798-11801.

251. Del Vecchio M, Bajetta E, Canova S, et al. Interleukin-12: biological properties and clinical application. Clin Cancer Res. 2007;13: $4677-4685$.
252. Leonard JP, Sherman ML, Fisher GL, et al. Effects of single-dose interleukin-12 exposure on interleukin-12-associated toxicity and interferon-gamma production. Blood. 1997;90:2541-2548.

253. Sarmiento UM, Riley JH, Knaack PA, et al. Biologic effects of recombinant human interleukin-12 in squirrel monkeys (Sciureus saimiri). Lab Invest. 1994;71:862-873.

254. Cohen J. IL-12 deaths: explanation and a puzzle. Science. 1995; 270:908.

255. Tare NS, Bowen S, Warrier RR, et al. Administration of recombinant interleukin-12 to mice suppresses hematopoiesis in the bone marrow but enhances hematopoiesis in the spleen. $J$ Interferon Cytokine Res.1995;15:377-383.

256. Lui VW, He Y, Falo L, Huang L. Systemic administration of naked DNA encoding interleukin-12 for the treatment of human papillomavirus DNA-positive tumor. Hum Gene Ther. 2002;13:177-185.

257. Parker JN, Gillespie GY, Love CE, et al. Engineered herpes simplex virus expressing IL-12 in the treatment of experimental murine brain tumors. Proc Natl Acad Sci U S A. 2000;97:2208-2213.

258. Jarnagin WR, Zager JS, Klimstra D, et al. Neoadjuvant treatment of hepatic malignancy: an oncolytic herpes simplex virus expressing IL-12 effectively treats the parent tumor and protects against recurrence-after resection. Cancer Gene Ther. 2003;10: 215-223.

259. Wong RJ, Chan MK, Yu Z, et al. Effective intravenous therapy of murine pulmonary metastases with an oncolytic herpes virus expressing interleukin-12. Clin Cancer Res. 2004;10:251-259.

260. Choi KJ, Kim JH, Lee YS, et al. Concurrent delivery of GM-CSF and B7-1 using an oncolytic adenovirus elicits potent antitumor effect. Gene Ther. 2006;13:1010-1020.

261. Kim HS, Kim-Schulze S, Kim DW, Kaufman HL. Host lymphodepletion enhances the therapeutic activity of an oncolytic vaccinia virus expressing 4-1BB ligand. Cancer Res. 2009;69:8516-8525.

262. Huang JH, Zhang SN, Choi KJ, et al. Therapeutic and tumor-specific immunity induced by combination of dendritic cells and oncolytic adenovirus expressing IL-12 and 4-1BBL. Mol Ther. 2010;18: 264-274

263. Galivo F, Diaz RM, Thanarajasingam U, et al. Interference of CD40Lmediated tumor immunotherapy by oncolytic VSV. Hum Gene Ther. 2010;21:439-450.

264. Todo T, Martuza RL, Dallman MJ, Rabkin SD. In situ expression of soluble B7-1 in the context of oncolytic herpes simplex virus induces potent antitumor immunity. Cancer Res. 2001;61:153-161.

265. Li JL, Liu HL, Zhang XR, et al. A phase I trial of intratumoral administration of recombinant oncolytic adenovirus overexpressing HSP70 in advanced solid tumor patients. Gene Ther. 2009;16:376-382.

266. Yoo JY, Ryu J, Gao R, et al. Tumor suppression by apoptotic and anti-angiogenic effects of mortalin-targeting adeno-oncolytic virus. J Gene Med. 2010;12:586-595.

267. Di Paolo NC, Tuve S, Ni S, et al. Effect of adenovirus-mediated heat shock protein expression and oncolysis in combination with low-dose cyclophosphamide treatment on antitumor immune responses. Cancer Res. 2006;66:960-969.

268. Huang XF, Ren W, Rollins L, et al. A broadly applicable, personalized heat shock protein-mediated oncolytic tumor vaccine. Cancer Res. 2003;63:7321-7329.

269. $\mathrm{Hu} \mathrm{ZB}, \mathrm{Wu} \mathrm{CT}$, Wang $\mathrm{H}$, et al. A simplified system for generating oncolytic adenovirus vector carrying one or two transgenes. Cancer Gene Ther. 2008;15:173-182.

270. Lonchay C, van der Bruggen P, Connerotte T, et al. Correlation between tumor regression and $\mathrm{T}$ cell responses in melanoma patients vaccinated with a MAGE antigen. Proc Natl Acad Sci U S A. 2004; 101(Suppl 2):14631-14638.

271. Harrop R, Connolly N, Redchenko I, et al. Vaccination of colorectal cancer patients with modified vaccinia Ankara delivering the tumor antigen 5T4 (TroVax) induces immune responses which correlate with disease control: a phase I/II trial. Clin Cancer Res. 2006;12: 3416-3424. 
272. Amato RJ, Drury N, Naylor S, et al. Vaccination of prostate cancer patients with modified vaccinia ankara delivering the tumor antigen 5T4 (TroVax): a phase 2 trial. J Immunother. 2008;31:577-585.

273. Kaufman HL, Lenz HJ, Marshall J, et al. Combination chemotherapy and ALVAC-CEA/B7.1 vaccine in patients with metastatic colorectal cancer. Clin Cancer Res. 2008;14:4843-4849.

274. Horig H, Lee DS, Conkright W, et al. Phase I clinical trial of a recombinant canarypoxvirus (ALVAC) vaccine expressing human carcinoembryonic antigen and the B7.1 co-stimulatory molecule. Cancer Immunol Immunother. 2000;49:504-514.

275. Harrop R, John J, Carroll MW. Recombinant viral vectors: cancer vaccines. Adv Drug Deliv Rev. 2006;58:931-947.

276. Elzey BD, Siemens DR, Ratliff TL, Lubaroff DM. Immunization with type 5 adenovirus recombinant for a tumor antigen in combination with recombinant canarypox virus (ALVAC) cytokine gene delivery induces destruction of established prostate tumors. Int J Cancer. 2001; 94:842-849.

277. Irvine KR, Chamberlain RS, Shulman EP, et al. Enhancing efficacy of recombinant anticancer vaccines with prime/boost regimens that use two different vectors. J Natl Cancer Inst. 1997;89:1595-1601.

278. Naslund TI, Uyttenhove C, Nordstrom EK, et al. Comparative prime-boost vaccinations using Semliki Forest virus, adenovirus, and ALVAC vectors demonstrate differences in the generation of a protective central memory CTL response against the P815 tumor. J Immunol. 2007;178:6761-6769.

279. Hodge JW, Poole DJ, Aarts WM, et al. Modified vaccinia virus ankara recombinants are as potent as vaccinia recombinants in diversified prime and boost vaccine regimens to elicit therapeutic antitumor responses. Cancer Res. 2003;63:7942-7949.

280. Hodge JW, McLaughlin JP, Kantor JA, Schlom J. Diversified prime and boost protocols using recombinant vaccinia virus and recombinant non-replicating avian pox virus to enhance T-cell immunity and antitumor responses. Vaccine. 1997;15:759-768.

281. Marshall JL, Hoyer RJ, Toomey MA, et al. Phase I study in advanced cancer patients of a diversified prime-and-boost vaccination protocol using recombinant vaccinia virus and recombinant nonreplicating avipox virus to elicit anti-carcinoembryonic antigen immune responses. J Clin Oncol. 2000;18:3964-3973.

282. Vigil A, Martinez O, Chua MA, Garcia-Sastre A. Recombinant Newcastle disease virus as a vaccine vector for cancer therapy. Mol Ther. 2008;16:1883-1890.

283. Power AT, Bell JC. Cell-based delivery of oncolytic viruses: a new strategic alliance for a biological strike against cancer. Mol Ther. 2007; 15:660-665.

284. Ilett EJ, Barcena M, Errington-Mais F, et al. Internalization of oncolytic reovirus by human dendritic cell carriers protects the virus from neutralization. Clin Cancer Res. 2011;17:2767-2776.

285. Liu C, Russell SJ, Peng KW. Systemic therapy of disseminated myeloma in passively immunized mice using measles virus-infected cell carriers. Mol Ther. 2010;18:1155-1164.

286. Mader EK, Maeyama Y, Lin Y, et al. Mesenchymal stem cell carriers protect oncolytic measles viruses from antibody neutralization in an orthotopic ovarian cancer therapy model. Clin Cancer Res. 2009;15: 7246-7255.

287. Qiao J, Kottke T, Willmon C, et al. Purging metastases in lymphoid organs using a combination of antigen-nonspecific adoptive $\mathrm{T}$ cell therapy, oncolytic virotherapy and immunotherapy. Nat Med. 2008;14: 37-44.

288. Hoffmann D, Bayer W, Wildner O. Local and distant immunemediated control of colon cancer growth with fusogenic membrane glycoproteins in combination with viral oncolysis. Hum Gene Ther. 2007; 18:435-450.

289. Yotnda P, Savoldo B, Charlet-Berguerand N, et al. Targeted delivery of adenoviral vectors by cytotoxic T cells. Blood. 2004;104: 2272-2280.

290. Thorne SH, Liang W, Sampath P, et al. Targeting localized immune suppression within the tumor through repeat cycles of immune celloncolytic virus combination therapy. Mol Ther. 2010;18:1698-1705.
291. Thomas DL, Doty R, Tosic V, et al. Myxoma virus combined with rapamycin treatment enhances adoptive $\mathrm{T}$ cell therapy for murine melanoma brain tumors. Cancer Immunol Immunother. 2011;60: 1461-1472.

292. Thorne SH, Negrin RS, Contag CH. Synergistic antitumor effects of immune cell-viral biotherapy. Science. 2006;311:1780-1784.

293. Raykov Z, Grekova S, Galabov AS, et al. Combined oncolytic and vaccination activities of parvovirus $\mathrm{H}-1$ in a metastatic tumor model. Oncol Rep. 2007;17:1493-1499.

294. Schirrmacher V. Clinical trials of antitumor vaccination with an autologous tumor cell vaccine modified by virus infection: improvement of patient survival based on improved antitumor immune memory. Cancer Immunol Immunother. 2005;54:587-598.

295. Schirrmacher V, Haas C, Bonifer R, et al. Human tumor cell modification by virus infection: an efficient and safe way to produce cancer vaccine with pleiotropic immune stimulatory properties when using Newcastle disease virus. Gene Ther. 1999;6:63-73.

296. Thorne SH, Contag $\mathrm{CH}$. Combining immune cell and viral therapy for the treatment of cancer. Cell Mol Life Sci. 2007;64:1449-1451.

297. Boudreau JE, Bridle BW, Stephenson KB, et al. Recombinant vesicular stomatitis virus transduction of dendritic cells enhances their ability to prime innate and adaptive antitumor immunity. Mol Ther. 2009; 17:1465-1472.

298. Heinzerling L, Kunzi V, Oberholzer PA, et al. Oncolytic measles virus in cutaneous T-cell lymphomas mounts antitumor immune responses in vivo and targets interferon-resistant tumor cells. Blood. 2005;106:2287-2294.

299. Mineta T, Rabkin SD, Yazaki T, et al. Attenuated multi-mutated herpes simplex virus- 1 for the treatment of malignant gliomas. Nat Med. 1995;1:938-943.

300. Harrington KJ, Karapanagiotou EM, Roulstone V, et al. Two-stage phase I dose-escalation study of intratumoral reovirus type 3 dearing and palliative radiotherapy in patients with advanced cancers. Clin Cancer Res. 2010;16:3067-3077.

301. Smith E, Breznik J, Lichty BD. Strategies to enhance viral penetration of solid tumors. Hum Gene Ther. 2011;22:1053-1060.

302. Liu TC, Kirn D. Systemic efficacy with oncolytic virus therapeutics: clinical proof-of-concept and future directions. Cancer Res. 2007;67: 429-432.

303. Law M, Hollinshead R, Smith GL. Antibody-sensitive and antibodyresistant cell-to-cell spread by vaccinia virus: role of the A33R protein in antibody-resistant spread. J Gen Virol. 2002;83:209-222.

304. Vanderplasschen A, Mathew E, Hollinshead M, et al. Extracellular enveloped vaccinia virus is resistant to complement because of incorporation of host complement control proteins into its envelope. Proc Natl Acad Sci U S A. 1998;95:7544-7549.

305. Ikeda K, Wakimoto H, Ichikawa T, et al. Complement depletion facilitates the infection of multiple brain tumors by an intravascular, replication-conditional herpes simplex virus mutant. JVirol. 2000;74: 4765-4775.

306. Ikeda K, Ichikawa T, Wakimoto H, et al. Oncolytic virus therapy of multiple tumors in the brain requires suppression of innate and elicited antiviral responses. Nat Med. 1999;5:881-887.

307. Dhar D, Spencer JF, Toth K, Wold WS. Pre-existing immunity and passive immunity to adenovirus 5 prevents toxicity caused by an oncolytic adenovirus vector in the Syrian hamster model. Mol Ther. 2009; 17:1724-1732.

308. Miest TS, Yaiw KC, Frenzke M, et al. Envelope-chimeric entrytargeted measles virus escapes neutralization and achieves oncolysis. Mol Ther. May 24, 2011.

309. Blechacz B, Russell SJ. Measles virus as an oncolytic vector platform. Curr Gene Ther. 2008;8:162-175.

310. Qiao J, Wang H, Kottke T, et al. Cyclophosphamide facilitates antitumor efficacy against subcutaneous tumors following intravenous delivery of reovirus. Clin Cancer Res. 2008;14:259-269.

311. Wakimoto H, Fulci G, Tyminski E, Chiocca EA. Altered expression of antiviral cytokine mRNAs associated with cyclophosphamide's enhancement of viral oncolysis. Gene Ther. 2004;11:214-223. 
312. Smakman N, van der Bilt JD, van den Wollenberg DJ, et al. Immunosuppression promotes reovirus therapy of colorectal liver metastases. Cancer Gene Ther. 2006;13:815-818.

313. Ungerechts G, Springfeld C, Frenzke ME, et al. An immunocompetent murine model for oncolysis with an armed and targeted measles virus. Mol Ther. 2007;15:1991-1997.

314. MacTavish H, Diallo JS, Huang B, et al. Enhancement of vaccinia virus based oncolysis with histone deacetylase inhibitors. PLoS One. 2010;5:e14462.

315. Kurozumi K, Hardcastle J, Thakur R, et al. Effect of tumor microenvironment modulation on the efficacy of oncolytic virus therapy. J Natl Cancer Inst. 2007;99:1768-1781.

316. Liu TC, Castelo-Branco P, Rabkin SD, Martuza RL. Trichostatin A and oncolytic HSV combination therapy shows enhanced antitumoral and antiangiogenic effects. Mol Ther. 2008;16:1041-1047.

317. Frentzen A, Yu YA, Chen N, et al. Anti-VEGF single-chain antibody GLAF-1 encoded by oncolytic vaccinia virus significantly enhances antitumor therapy. Proc Natl Acad Sci U S A. 2009;106: 12915-12920.

318. Tysome J, Wang P, Alusi G, et al. Lister vaccine strain of vaccinia virus armed with the endostatin-angiostatin fusion gene: a superior oncolytic virus to d11520 (ONYX-015) for human head and neck cancer. Hum Gene Ther. 2011;22:1101-1108.

319. Tysome JR, Briat A, Alusi G, et al. Lister strain of vaccinia virus armed with endostatin-angiostatin fusion gene as a novel therapeutic agent for human pancreatic cancer. Gene Ther. 2009;16:1223-1233.

320. Tysome JR, Lemoine NR, Wang Y. Combination of anti-angiogenic therapy and virotherapy: arming oncolytic viruses with anti-angiogenic genes. Curr Opin Mol Ther. 2009;11:664-669.

321. Su C, Na M, Chen J, et al. Gene-viral cancer therapy using dualregulated oncolytic adenovirus with antiangiogenesis gene for increased efficacy. Mol Cancer Res. 2008;6:568-575.

322. Fang L, Pu YY, Hu XC, et al. Antiangiogenesis gene armed tumortargeting adenovirus yields multiple antitumor activities in human HCC xenografts in nude mice. Hepatol Res. 2009;40:216-228.

323. Guse K, Diaconu I, Rajecki M, et al. Ad5/3-9HIF-delta24-VEGFR-1-Ig, an infectivity enhanced, dual-targeted and antiangiogenic oncolytic adenovirus for kidney cancer treatment. Gene Ther. 2009;16: 1009-1020.

324. Kottke T, Thompson J, Diaz RM, et al. Improved systemic delivery of oncolytic reovirus to established tumors using preconditioning with cyclophosphamide-mediated Treg modulation and interleukin-2. Clin Cancer Res. 2009;15:561-569.

325. Willmon C, Diaz RM, Wongthida P, et al. Vesicular stomatitis virus-induced immune suppressor cells generate antagonism between intratumoral oncolytic virus and cyclophosphamide. Mol Ther. 2011; 19:140-149.
326. Kottke T, Chester J, Ilett E, et al. Precise scheduling of chemotherapy primes VEGF-producing tumors for successful systemic oncolytic virotherapy. Mol Ther. July 26, 2011.

327. Bajzer Z, Carr T, Josic K, et al. Modeling of cancer virotherapy with recombinant measles viruses. J Theor Biol. 2008;252:109-122.

328. Biesecker M, Kimn JH, Lu H, et al. Optimization of virotherapy for cancer. Bull Math Biol. 2010;72:469-489.

329. Dingli D, Cascino MD, Josic K, et al. Mathematical modeling of cancer radiovirotherapy. Math Biosci. 2006;199:55-78.

330. Dingli D, Offord C, Myers R, et al. Dynamics of multiple myeloma tumor therapy with a recombinant measles virus. Cancer gene therapy. 2009;16:873-882.

331. Friedman A, Tian JP, Fulci G, et al. Glioma virotherapy: effects of innate immune suppression and increased viral replication capacity. Cancer research. 2006;66:2314-2319.

332. Karev GP, Novozhilov AS, Koonin EV. Mathematical modeling of tumor therapy with oncolytic viruses: effects of parametric heterogeneity on cell dynamics. Biol Direct. 2006;1:30.

333. Novozhilov AS, Berezovskaya FS, Koonin EV, Karev GP. Mathematical modeling of tumor therapy with oncolytic viruses: regimes with complete tumor elimination within the framework of deterministic models. Biol Direct. 2006;1:6.

334. Paiva LR, Binny C, Ferreira SC Jr, Martins ML. A multiscale mathematical model for oncolytic virotherapy. Cancer Res. 2009;69: 1205-1211.

335. Rommelfanger DM, Offord CP, Dev J, et al. Dynamics of melanoma tumor therapy with vesicular stomatitis virus: explaining the variability in outcomes using mathematical modeling. Gene Ther. September 15, 2011. [Epub ahead of print.]

336. Wein LM, Wu JT, Kirn DH. Validation and analysis of a mathematical model of a replication-competent oncolytic virus for cancer treatment: implications for virus design and delivery. Cancer Res. 2003;63:1317-1324.

337. Wodarz D, Komarova N. Towards predictive computational models of oncolytic virus therapy: basis for experimental validation and model selection. PloS One. 2009;4:e4271.

338. Wu JT, Byrne HM, Kirn DH, Wein LM. Modeling and analysis of a virus that replicates selectively in tumor cells. Bull Math Biol. 2001;63: 731-768.

339. Wu JT, Kirn DH, Wein LM. Analysis of a three-way race between tumor growth, a replication-competent virus and an immune response. Bull Math Biol. 2004;66:605-625.

340. Eftimie R, Dushoff J, Bridle BW, et al. Multi-stability and multiinstability phenomena in a mathematical model of tumor-immunevirus interactions. Bull Math Biol. 2011;73:2932-2961.
Virus Adaptation and Treatment

\section{Publish your work in this journal}

Virus Adaptation and Treatment is an international, peer-reviewed open access journal focusing on the study of virology, viral adaptation and the development and use of antiviral drugs and vaccines to achieve improved outcomes in infection control and treatment. The journa welcomes original research, basic science, clinical \& epidemiological

\section{Dovepress}

studies, reviews \& evaluations, expert opinion and commentary, case reports and extended reports. The manuscript management system is completely online and includes a very quick and fair peer-review system, which is all easy to use. Visit http://www.dovepress.com/ testimonials.php to read real quotes from published authors. 